\title{
Clinical significance of cytogenetic aberrations in bone marrow of patients with diffuse large B-cell lymphoma: prognostic significance and relevance to histologic involvement
}

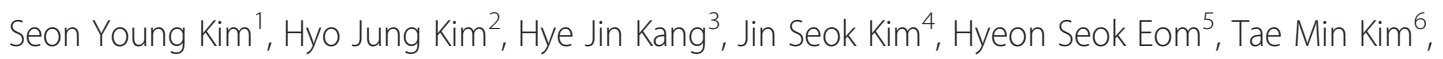
Sung-Soo Yoon ${ }^{6}$, Cheolwon Suh ${ }^{7 *}$, Dong Soon Lee ${ }^{1 *}$ and Korean Society of Hematology Lymphoma Working Party

\begin{abstract}
Background: Although knowledge of the genetics of diffuse large B-cell lymphoma (DLBCL) has been increasing, little is known about the characteristics and prognostic significance of cytogenetic abnormalities and the clinical utility of cytogenetic studies performed on bone marrow (BM) specimens. To investigate the significance of isolated cytogenetic aberrations in the absence of histologic BM involvement, we assessed the implication of cytogenetic staging and prognostic stratification by a retrospective multicenter analysis of newly diagnosed DLBCL patients.

Methods: We analyzed cytogenetic and clinical data from 1585 DLBCL patients whose BM aspirates had been subjected to conventional karyotyping for staging. If available, interphase fluorescence in situ hybridization (FISH) data were also collected from patients.

Results: Histologic BM involvement were found in 259/1585 (16.3\%) patients and chromosomal abnormalities were detected in $192(12.1 \%)$ patients (54 patients with single abnormalities and 138 patients with 2 or more abnormalities). Isolated cytogenetic aberrations (2 or more abnormalities) without histologic involvement were found in 21 patients (1.3\%). Two or more cytogenetic abnormalities were associated with inferior overall survival (OS) compared with a normal karyotype or single abnormality in both patients with histologic BM involvement (5-year OS, 22.0\% vs. 52.7\%; $P<0.001)$ and those without BM involvement (31.8\% vs. 66.5\%; $P<0.001)$. This result demonstrated that BM cytogenetic results have a significant prognostic impact that is independent of BM histology. The following abnormalities were most frequently observed: rearrangements involving 14q32, 19q13, 19p13, 1p, 3q27, and 8q24; del(6q); dup(1q); and trisomy 18. In univariate analysis, several specific abnormalities including abnormalities at 16q22-q24, 6p21-p25, 12q22-q24, and -17 were associated with poor prognosis. Multivariate analyses performed for patients who had either chromosomal abnormalities or histologic BM involvement, revealed IPI high risk, $\geq 2$ cytogenetic abnormalities, and several specific chromosomal abnormalities, including abnormalities at 19p13, 12q22-q24, 8q24, and 19q13 were significantly associated with a worse prognosis.

(Continued on next page)
\end{abstract}

\footnotetext{
* Correspondence: csuh@amc.seoul.kr; soonlee@plaza.snu.ac.kr

${ }^{7}$ Department of Internal Medicine, Asan Medical Center, University of Ulsan

College of Medicine, 86 Asanbeongwon-gil, Songpa-gu, Seoul 138-736,

Republic of Korea

'Department of Laboratory Medicine, Seoul National University Hospital, Seoul National University College of Medicine, 101 Daehak-ro, Jongno-gu,

Seoul 110-744, Republic of Korea

Full list of author information is available at the end of the article
} 
(Continued from previous page)

Conclusions: We suggest that isolated cytogenetic aberrations can be regarded as BM involvement and cytogenetic evaluation of BM improves staging accuracy along with prognostic information for DLBCL patients.

Keywords: Diffuse large B-cell lymphoma, Cytogenetics, Chromosomal abnormalities, Bone marrow involvement, Prognosis

\section{Introduction}

Bone marrow (BM) evaluations are an essential part of the routine staging of diffuse large B-cell lymphoma (DLBCL) [1]. DLBCL with BM involvement is rated as Ann Arbor stage IV, resulting in higher International Prognostic Index (IPI) scores and, thus, poor prognoses [2]. BM has traditionally been evaluated by morphological examination, which commonly includes immunohistochemical (IHC) staining. Histologic BM involvement has been reported in $10-30 \%$ of DLBCL cases [3,4]. Recently, additional efforts have been made to detect even a minimal involvement of lymphoma cells using flow cytometry and molecular or cytogenetic techniques. With the application of these complementary tests, approximately $10-20 \%$ of cases that were initially classified as histologically negative have been reassessed as having BM involvement [5-7]. In a previous study in which BM was evaluated using flow cytometry and immunoglobulin gene rearrangement analysis, a change in IPI was noted in $11.5 \%$ on immunophenotyping alone, and $14.1 \%$ cases on immunophenotyping and molecular testing. The revised IPI model using immunophenotyping provided better differentiation between the IPI prognostic categories [6].

Classical cytogenetic studies of BM specimens play a pivotal role in the diagnosis and prognostic prediction of many hematologic malignancies. However, the cytogenetic data concerning DLBCL tissues are limited. DLBCL is a group of B-cell malignancies that are extremely heterogeneous histopathologically, biologically, and clinically. Consistent with this heterogeneity, various chromosomal abnormalities have been reported in patients with DLBCL [8]. Correlations between cytogenetic data and clinical outcomes have been attempted for DLBCL; however, controversy remains concerning the prognostic significance of these data, most of which were obtained before the initiation of R-CHOP (rituximab, cyclophosphamide, doxorubicin, vincristine, and prednisolone) therapy.

In Korea, cytogenetic studies of BM specimens using the G-banding technique have been a routine practice in many hospitals, primarily to aid in the detection of $\mathrm{BM}$ involvement when staging newly diagnosed DLBCL patients. Cytogenetic study of the BM can overcome the limitations of tumor tissue cytogenetics such as fuzzy chromosomes, failure in obtaining cells in metaphase, and contamination. The presence of chromosomal aberrations in the absence of histologic involvement of BM raises the question as to whether the abnormalities truly originate from BM involving-lymphoma cells or if the aberrations are just cytogenetic noise. In the present study, to investigate the characteristics of chromosomal aberrations in the BM of DLBCL patients and to determine their prognostic significance, we retrospectively analyzed cytogenetic data of BM specimens submitted for staging from a large series of DLBCL patients.

\section{Materials and methods}

\section{Study population}

A total of 1585 DLBCL cases were referred from six tertiary hospitals in Korea: Seoul National University Hospital ( $\mathrm{n}=646$; 1996 to 2011); Asan Medical Center ( $\mathrm{n}=484 ; 2001$ to 2009); National Cancer Center of Korea ( $\mathrm{n}=236 ; 2004$ to 2009); Yonsei University Hospital ( $\mathrm{n}=118 ; 2004$ to 2009); Hallym University Hospital ( $\mathrm{n}=57 ; 2004$ to 2009); and Korea Cancer Center Hospital ( $\mathrm{n}=44 ; 2005$ to 2009). The cases were selected on the basis of diagnoses established according to the 2008 World Health Organization (WHO) classification criteria for primary tissue biopsy specimens [9]. BM biopsies were conducted for staging purposes at the time of the initial diagnosis. The treatment protocols were heterogeneous but generally conformed to international standards, including combination chemotherapy using CHOP-like regimens for front-line therapy, as well as salvage chemotherapy followed by stem cell transplantation for refractory cases. The baseline patient characteristics are summarized in Table 1. All of the patients were Korean, and the median age was 57 years (range, 2-91 years). A total of 1128 patients $(71.2 \%)$ received $\mathrm{R}-\mathrm{CHOP}$ as the initial therapy, 380 patients $(24.0 \%)$ received a therapy other than R-CHOP (157 CHOP and 223 other regimens), and 77 patients $(4.9 \%)$ received an unknown treatment or no treatment. The median follow-up time was 25.7 months (range, 0.1-211.1 months).This study was reviewed and approved by the institutional review board of each hospital.

\section{Histopathology}

A primary DLBCL diagnosis was established by examining hematoxylin and eosin (H\&E)-stained sections of diagnostic biopsies from various tissues with IHC stains, including 
Table 1 The baseline characteristics of 1585 DLBCL patients and a comparison of the clinical features of the patients with histologic $\mathrm{BM}$ involvement $\left(\mathrm{BMI}_{\text {histo }}{ }^{+}\right)$and those without $\left(\mathrm{BMI}_{\text {histo }}{ }^{-}\right)$

\begin{tabular}{|c|c|c|c|c|}
\hline Characteristics & $\begin{array}{c}\text { Total } \\
(\mathrm{n}=1585)\end{array}$ & $\begin{array}{c}\text { BMI }_{\text {histo }}{ }^{+} \\
(\mathrm{n}=259)\end{array}$ & $\begin{array}{l}\mathrm{BMI}_{\text {histo }}{ }^{-} \\
(\mathrm{n}=1326)\end{array}$ & $P$ value ${ }^{*}$ \\
\hline Median age, years (range) & $57.4(1.9-90.9)$ & $59.0(1.9-86.4)$ & $57.0(5.3-90.9)$ & 0.013 \\
\hline Age $>60 \mathrm{yr}$ & $679 / 1585(42.8)$ & $124 / 259(47.9)$ & $555 / 1326(41.9)$ & 0.073 \\
\hline Gender (male/female, \%male) & $881 / 704(55.6)$ & $132 / 127(51.0)$ & $749 / 577(56.5)$ & 0.102 \\
\hline B symptoms & $394 / 1585(24.9)$ & $135 / 259(52.1)$ & 259/1326 (19.5) & $<0.001$ \\
\hline$E C O G \geq 2$ & 226/1585 (14.3) & $86 / 259(33.2)$ & $140 / 1326(10.6)$ & $<0.001$ \\
\hline High serum LDH & $975 / 1585(61.5)$ & $203 / 259(78.4)$ & $772 / 1326(58.2)$ & $<0.001$ \\
\hline Stage 3 or 4 & $822 / 1585(52.6)$ & $259 / 259(100)$ & $574 / 1326(43.3)$ & $<0.001$ \\
\hline Stage 3 or 4 , excluding BM status & $809 / 1585(51.0)$ & $237 / 259(91.5)$ & $572 / 1326(43.1)$ & $<0.001$ \\
\hline Extranodal involvement $\geq 2$ sites & 497/1585 (31.4) & $193 / 259(74.5)$ & $304 / 1326(22.9)$ & $<0.001$ \\
\hline \multicolumn{5}{|l|}{ International Prognostic Index } \\
\hline Low risk & $392 / 1585(24.7)$ & $0 / 259(0)$ & 392/1326 (29.6) & \multirow[t]{4}{*}{$<0.001$} \\
\hline Low/intermediate risk & $462 / 1585(29.2)$ & $33 / 259(12.7)$ & $427 / 1326(32.4)$ & \\
\hline High/intermediate risk & $467 / 1585(29.5)$ & $114 / 259(44.0)$ & $353 / 1326(26.6)$ & \\
\hline High risk & 264/1585 (16.7) & $112 / 259(43.2)$ & $152 / 1315(11.5)$ & \\
\hline Non-GCB type & $500 / 877(57.0)$ & $95 / 150(63.3)$ & 405/727 (55.7) & 0.086 \\
\hline CD5-positive & $33 / 341(9.7)$ & $7 / 57(12.3)$ & $26 / 284(9.2)$ & 0.466 \\
\hline \multicolumn{5}{|l|}{ Initial treatment } \\
\hline $\mathrm{R}-\mathrm{CHOP}$ & 1128/1585 (71.2) & $146 / 259(56.4)$ & $982 / 1326(74.1)$ & \multirow[t]{4}{*}{$<0.001$} \\
\hline $\mathrm{CHOP}$ & 157/1585 (9.9) & $30 / 259(11.6)$ & 127/1326 (9.6) & \\
\hline Other treatment & 223/1585 (14.1) & $53 / 259(20.5)$ & $170 / 1326(12.8)$ & \\
\hline No therapy & 77/1585 (4.9) & 30/259 (11.6) & $47 / 1326(3.5)$ & \\
\hline \multicolumn{5}{|l|}{ Initial treatment response } \\
\hline$C R$ & 1020/1394 (73.2) & 118/207 (57.0) & $902 / 1187(76.0)$ & \multirow[t]{4}{*}{$<0.001$} \\
\hline PR & 268/1394 (19.2) & $51 / 207(24.6)$ & 217/1187 (18.3) & \\
\hline SD & 33/1394 (2.4) & $8 / 207(3.9)$ & 25/1187 (2.1) & \\
\hline PD & 73/1394 (5.2) & $30 / 207(14.5)$ & 43/1187 (3.6) & \\
\hline \multicolumn{5}{|l|}{ Follow-up data } \\
\hline Deaths & $484 / 1585(30.5)$ & $134 / 259(51.7)$ & $350 / 1326(26.4)$ & $<0.001$ \\
\hline Median follow-up, months (range) & $25.7(0.1-211.1)$ & $12.0(0.1-141.4)$ & $29.5(0.1-211.1)$ & $<0.001$ \\
\hline
\end{tabular}

CD3, CD20, CD5, CD10, BCL2, BCL6, and IRF/MUM1, according to the diagnostic protocol of each institute. The type of DLBCL based on the cell of origin, either germinal center B-cell-like (GCB) or non-GCB, was defined in 877 cases using the algorithm of Hans et al. [10]. In general, the BM biopsies were performed bilaterally. Wright-stained BM smears and H\&E-stained sections of BM biopsies were reviewed by hematopathologists at each institute. IHC staining was performed at the discretion of hematopathologists at each institute. The BM reports were reviewed centrally, and additional
IHC staining targeting CD3, CD20, and CD79a was performed for cases with discrepant results between histologic examination and cytogenetic tests, to confirm the initial BM histologic diagnosis. The presence of benign lymphoid aggregates was distinguished from lymphoma involvement using previously described criteria [11]. Flow cytometric analysis was performed for some cases with diffuse infiltration of lymphoma cells $(n=46)$. According to the $\mathrm{BM}$ results, the cases were dichotomized into those with histological $\mathrm{BM}$ involvement $\left(\mathrm{BMI}_{\text {histo }}{ }^{+}\right)$and those without $\left(\mathrm{BMI}_{\text {histo }}{ }^{-}\right)$. 


\section{Cytogenetic analysis of BM}

Conventional cytogenetic tests using the G-banding technique were performed on BM aspirates from all the patients. The cytogenetic tests were performed locally, and the reports were reviewed centrally by two of the investigators (SYK and DSL). Cytogenetic studies using standard techniques were performed as a part of the diagnostic work-up at the time of initial diagnosis. Conventional G-banding cytogenetic analysis was performed using the short-term unstimulated culture $(24-48 \mathrm{~h})$ of $\mathrm{BM}$ cells. At least 20 metaphases were analyzed, whenever possible. Clonal abnormalities were defined as at least two cells with the same aberration if the aberration is a chromosome gain or a structural rearrangement, or 3 or more cells with the same chromosome missing. The karyotypes were recorded according to the International System for Human Cytogenetic Nomenclature (ISCN) [12]. We classified the karyotype results according to the complexity of the chromosomal abnormalities observed. A complex karyotype was defined as $\geq 3$ chromosomal abnormalities, in accordance with previous studies [13,14]. A monosomal karyotype was defined as either a single autosomal monosomy in the presence of one or more structural aberration or two or more distinct autosomal chromosome monosomies $[15,16]$. In the interpretation of specific abnormalities, numerical aberrations included gains, losses of chromosomes (aneuploidy) and changes in ploidy. Structural aberrations included abnormalities such as deletions, translocations, isochromosomes, and duplications. Translocations included balanced reciprocal translocations and translocations with unknown partners (additions).

Fluorescence in situ hybridization (FISH) was performed in some cases $(n=235)$. The following target regions were investigated using the accompanying probes: 14q32/ $I G H$ using an $I G H$ dual-color, break-apart rearrangement probe ( $\mathrm{n}=201$ ); $c M Y C / I G H$ using a dual-color, dualfusion probe $(\mathrm{n}=11)$; $B C L 2 / I G H$ using a dual-color, dualfusion probe $(\mathrm{n}=29) ; 9 \mathrm{p} 21 / p 16$ using a $p 16 / C E P 9$ dual-color probe $(\mathrm{n}=178)$; 3q27/BCL6 using a BCL6 dual-color, break-apart rearrangement probe $(\mathrm{n}=95)$; $8 \mathrm{q} 24 / c M Y C$ using a $c M Y C$ break-apart probe $(\mathrm{n}=39)$ or a $c M Y C / I G H$ using dual-color, dual-fusion probe $(\mathrm{n}=11)$; $1 \mathrm{q} 25$ using a $1 \mathrm{p} 32 / 1 \mathrm{q} 25$ probe $(\mathrm{n}=49) ; 17 \mathrm{p} 13 /$ TP53 using a $P 53$ probe $(\mathrm{n}=34)$; and $18 \mathrm{q} 23 / B C L 2$ using a $B C L 2 / I G H$ dual-color, dual-fusion probe $(\mathrm{n}=29$; all probes from Abbott/Vysis, Downers Grove, IL, USA). We analyzed interphase cells according to the manufacturer's instruction and the ISCN criteria. At least 200 nuclei per sample were scored for normal or abnormal FISH signals. The normal cut-off values for translocation, deletion, or amplification were based on the mean $( \pm 3 S D)$ and the binomial distribution function [17] analyzed of 40 negative controls. The cut-off values for $I G H$ break-apart probe was $2 \%$, and $c M Y C / I G H$ probe was $<0.5 \%$.

\section{Statistical analyses}

The data were compared using the Mann-Whitney and Kruskal-Wallis tests for continuous variables and $x^{2}$ test for categorical variables. Each numerical abnormality and the specific locus of each structural abnormality were dichotomized as present or absent, and hierarchical clustering was performed using Pearson correlation distance metrics and Wald linkage tests. The probabilities of overall survival (OS) and progression-free survival (PFS) [18] were plotted according to the Kaplan-Meier method, and the log-rank test with Bonferroni correction for multiple testing was used to compare the survival curves. A multivariate analysis was performed using the Cox regression method. The following parameters were analyzed for multivariate analysis: advanced age, gender, IPI risk groups, history of $\mathrm{R}-\mathrm{CHOP}$ treatment, $\mathrm{BMI}_{\text {histo }}{ }^{+}$ vs $\mathrm{BMI}_{\text {histo }}{ }^{-}, \geq 2$ abnormalities vs normal karyotype or 1 abnormality, and presence of several specific cytogenetic abnormalities abnormalities, which were associated with poor prognosis in univariate analysis and found in a minimum of 5 patients. Variables in the final model were selected using stepwise selection procedure with a threshold of $P=0.05$. The statistical analyses were performed using SPSS version 15 (SPSS, Chicago, IL, USA) and the R statistical package (R Development Team 2012). A probability level of 0.05 was considered significant in the univariate analysis. When multiple hypothesis testing was performed, the $P$ value was adjusted by Bonferroni correction.

\section{Results}

Comparison of histology and conventional cytogenetic tests for the detection of BM involvement

A total of 259 patients (16.3\%) had BM involvement, as determined through histologic examinations. Among the $259 \mathrm{BMI}_{\text {histo }}{ }^{+}$patients, 181 (69.9\%) exhibited lymphoma cells on BM aspirate smears, and all 259 patients demonstrated lymphoma involvement in a BM biopsy. The median percentage of lymphoma cells in the BM aspirate smear was $6.2 \%$ (range, 0-98\%). Compared with the $\mathrm{BMI}_{\text {histo }}{ }^{-}$group, the $\mathrm{BMI}_{\text {histo }}{ }^{+}$group had a poorer performance status, higher lactate dehydrogenase (LDH) levels, more advanced stage tumors, and more prevalent extranodal involvement; consequently, these patients had higher IPI scores (Table 1).

Chromosomal abnormalities were detected in 192/ 1585 patients (12.1\%), of whom $124 / 192$ (64.6\%) were $\mathrm{BMI}_{\text {histo }}{ }^{+}$(Table 2). Among the 192 patients with chromosomal aberrations, $42(21.9 \%)$ exhibited the following single numerical aberrations: 33 patients had Y chromosome loss; 7 patients had a loss or gain of other single chromosomes; and 2 patients had hyperdiploid clones (Additional file 1: Table S1). Among the 42 patients with the above single numerical aberrations, $4 / 42$ (9.5\%) were 
Table 2 A comparison of the histologic and conventional cytogenetic analyses

\begin{tabular}{|c|c|c|c|c|c|c|}
\hline \multirow[t]{2}{*}{ Cytogenetic findings } & \multirow{2}{*}{$\begin{array}{c}\text { No. of } \\
\text { patients }\end{array}$} & \multirow{2}{*}{$\begin{array}{l}\text { No. of } \\
\text { BMl } l_{\text {histo }}^{+} \\
\text {cases }\end{array}$} & \multicolumn{3}{|c|}{ Percentage of abnormal metaphases } & \multirow{2}{*}{$\begin{array}{c}\text { BM } \\
\text { lymphoma } \\
\text { cell } \\
\text { percentage }\end{array}$} \\
\hline & & & $\mathrm{BMI}_{\text {histo }}^{+}$ & $\mathrm{BMI}_{\text {histo }}^{-}$ & $P$ value ${ }^{*}$ & \\
\hline Normal karyotype & $1393(87.9)$ & 135/1393 (9.7) & NA & NA & NA & $1(0-98)$ \\
\hline Abnormal karyotype & $192(12.1)$ & 124/192 (64.6) & $49(8-100)$ & $25(5-100)$ & $<0.001$ & $18(0-95)$ \\
\hline Single abnormality & $54(3.4)$ & $7 / 54(13.0)$ & $35(8-100)$ & $25(9-100)$ & 0.697 & $5(0-86)$ \\
\hline Single numerical abnormality & $42(2.6)$ & $4 / 42(9.5)$ & $60(27-100)$ & $21(10-100)$ & 0.038 & $3(0-86)$ \\
\hline Loss of $Y$ & $33(2.1)$ & $3 / 33(9.1)$ & $70(50-100)$ & $20(10-100)$ & 0.021 & $6(0-86)$ \\
\hline Loss of another single chromosome & $7(0.4)$ & $1 / 7(14.3)$ & 27 & $22(15-70)$ & 0.617 & $0^{\ddagger}$ \\
\hline Polyploidy & $2(0.1)$ & $0 / 2(0)$ & NA & $27(22-31)$ & NA & NA \\
\hline Single structural abnormality & $12(0.8)$ & $3 / 12(25.0)$ & $15(8-35)$ & $67(9-100)$ & 0.090 & $5(0-29)$ \\
\hline Multiple abnormalities & $138(8.8)$ & $117 / 138(84.8)$ & $50(8-100)$ & $25(5-100)$ & 0.009 & $19(0-95)$ \\
\hline 2 abnormalities & $10(0.7)$ & $6 / 10(60.0)$ & $67(10-100)$ & $23(15-58)$ & 0.394 & $41(12-73)$ \\
\hline 1 structural and 1 numerical abnormality & $6(0.4)$ & $4 / 6(66.7)$ & $67(13-92)$ & $39(20-58)$ & 0.355 & $27(12-50)$ \\
\hline 2 structural abnormalities & $4(0.3)$ & $2 / 4(50.0)$ & $55(10-100)$ & $20(15-25)$ & 0.999 & $61(49-73)$ \\
\hline$\geq 3$ abnormalities & $128(8.1)$ & $111 / 128(86.7)$ & $48(8-100)$ & $30(5-100)$ & 0.024 & $18(0-95)$ \\
\hline (complex karyotype) & & & & & & \\
\hline
\end{tabular}

${ }^{*} P$ value by the Mann-Whitney $U$ test comparing the percentage of abnormal metaphases between the $\mathrm{BMI}_{\text {histo }}{ }^{+}$and $\mathrm{BMI}_{\text {histo }}{ }^{-}$groups.

${ }^{\dagger}$ Lymphoma cell percentage calculated from bone marrow aspirate smears.

FThis case showed diffuse DLBCL involvement in the bone marrow biopsy.

The data represent the median (range) for continuous variables or the number (percentage) for categorical variables, unless otherwise indicated.

Abbreviations: $\mathrm{BMI}_{\mathrm{histo}}{ }^{+}$, histologic bone marrow involvement; $\mathrm{BMI}_{\mathrm{histo}}{ }^{-}$, no evidence of histologic bone marrow involvement; $\mathrm{NA}$, not applicable. 
$\mathrm{BMI}_{\text {histo }}{ }^{+}$, which was not significantly different from the proportion of $\mathrm{BMI}_{\text {histo }}{ }^{+}$patients with normal karyotypes (135/1393, 9.7\%; $P=0.971)$. There were 12 patients with single structural abnormalities, of whom 4 patients exhibited single deletions $[\operatorname{del}(13 q)$ in 2 patients and $\operatorname{del}(20)(q 11.2)$ in 2 patients], and 1 patient had a duplication of $\mathrm{Y}$ chromosome; none were $\mathrm{BMI}_{\text {histo }}{ }^{+}$. Seven patients exhibited translocations, including $\mathrm{t}(2 ; 11)(\mathrm{p} 21$; q23), t(4;10)(q28;p13), t(6;18)(p23;p11), t(10;11)(q22;q23), add(12)(q24), $\mathrm{t}(3 ; 14)(\mathrm{q} 27 ; \mathrm{q} 32)$, and $\mathrm{t}(14 ; 18)(\mathrm{q} 32 ; \mathrm{q} 21)$; the patients with the latter 3 types of abnormalities were $\mathrm{BMI}_{\text {histo }}{ }^{+}$. The remaining $138 / 192$ patients $(71.9 \%)$ exhibited $\geq 2$ aberrations. Ten of these patients exhibited 2 chromosomal abnormalities: 6 patients had 1 structural aberration and 1 numerical aberration, and 4 patients had 2 structural aberrations. Among the patients with 2 chromosomal abnormalities, $6 / 10(60 \%)$ were $\mathrm{BMI}_{\text {histo }}{ }^{+}$. A total of 128 patients exhibited complex karyotypes. Many of these patients had highly complex abnormalities, with a median of 9 total chromosomal abnormalities (range, 325) including many structural abnormalities (median, 7; range, 0-20). Among the patients with complex karyotypes, $111 / 128$ were $\mathrm{BMI}_{\text {histo }}{ }^{+}$(86.7\%). Consequently, 117/ 138 patients $(84.8 \%)$ with $\geq 2$ chromosomal aberrations were $\mathrm{BMI}_{\text {histo }}{ }^{+}$. Among the patients with complex karyotypes, the percentages of abnormal metaphases were higher in the $\mathrm{BMI}_{\text {histo }}{ }^{+}$group compared with the $\mathrm{BMI}_{\text {histo }}{ }^{-}$group $(P=0.024)$. The percentages of metaphases with $\mathrm{Y}$ chromosome losses were higher in the $\mathrm{BMI}_{\text {histo }}{ }^{+}$group $(P=0.021)$, however, there was no significant differences in the number of metaphases for patients with loss of single chromosomes other than Y, polyploidy or single structural abnormalities between the $\mathrm{BMI}_{\text {histo }}{ }^{+}$and $\mathrm{BMI}_{\text {histo }}{ }^{-}$groups. Among the patients with complex karyotypes, only a weak correlation was found between the percentage of metaphases with aberrant karyotypes and the percentage of lymphoma cells in BM aspirates $(r=0.365)$. Our results indicate that a finding of BM cytogenetic aberrations involving single numerical abnormalities alone cannot be regarded as sufficient evidence of BM involvement of lymphoma cells, considering the low concordance between such findings and the histologic results. If multiple chromosomal abnormalities were considered as definite evidence of the presence of lymphoma cells, the 21/1585 (1.3\%) patients with isolated cytogenetic aberrations without histologic involvement would be reassessed as having $\mathrm{BM}$ involvement.

\section{Chromosomal abnormalities and clinical and biological characteristics}

We compared the clinical and biological characteristics of the $\mathrm{BMI}_{\text {histo }}{ }^{+}$patients with normal karyotypes to patients with abnormal karyotypes. Compared with the patients with normal karyotypes, the patients with a single numerical abnormality presented with less aggressive disease, as evidenced by their lower LDH levels, less involvement of extranodal sites, and lower IPI risk scores. In contrast, the patients with $\geq 2$ chromosomal abnormalities had a poorer performance status, higher LDH levels, more advanced disease stages, more prevalent extranodal involvement, and thus, higher IPI scores (Table 3).

\section{Comparison of BM histology and FISH results}

The histologic examinations, conventional cytogenetics, and FISH results of a limited number of patients were compared (Table 4). Among the 235 patients for whom FISH studies were performed, there were $3 \mathrm{BMI}_{\text {histo }}{ }^{-}$patients with normal karyotypes and abnormal 14q32/IGH FISH results, although the frequencies of abnormal FISH signals were low $(5 \%, 7 \%$, and $8 \%)$. A single $\mathrm{BMI}_{\text {histo }}{ }^{-}$patient exhibited cytogenetic abnormalities of the $8 \mathrm{q} 24$ locus despite normal FISH results using a specific probe.

\section{Characteristics of cytogenetic aberrations}

We analyzed the frequencies of specific cytogenetic aberrations among the patients with chromosomal aberrations other than single numerical aberrations $(n=150)$ (Figure 1). The chromosomes most frequently involved were chromosome $1,3,6,14$, and 18 . The most common numerical aberrations were trisomy 18, trisomy 7 , trisomy 3 , loss of $\mathrm{Y}$, and loss of 13 . The predominant structural aberrations involved the following loci: rearrangements involving 14q32, 19q13, 19p13, 1p32p36, 3q27, 8q24, 18q21-q23, 1cen-1q12, 9p22-p24, 11q23-q25, 16q22-q24, and; deletions of 6q; and duplications of 1q. The well-known oncogenes and lymphomarelated genes that exhibited frequent breakpoints, including BCL6 (3q27), JAK2 (9p22), IGH (14q32), and $B C L 2$ (18q21), as well as other possible oncogenes with breakpoints, are indicated in Figure 1D. Monosomal karyotypes were observed in 70 patients (46.7\%), and hyperdiploidy was noted in 24 cases $(16.0 \%)$. Reciprocal translocations were observed in 90 patients (60.0\%); among them, 19 carried reciprocal translocations involving the $14 \mathrm{q} 32 /$ IGH region with defined partners. The translocation partners were the following: $t(8 ; 14)(\mathrm{q} 24 ; \mathrm{q} 32)$ in 5 cases; $\mathrm{t}(14 ; 18)(\mathrm{q} 32 ; \mathrm{q} 21)$ in 4 cases; $\mathrm{t}(3 ; 14)(\mathrm{q} 27 ; \mathrm{q} 32)$ in 3 cases; $\mathrm{t}(1 ; 14)(\mathrm{q} 21 ; \mathrm{q} 32) ; \mathrm{t}(1 ; 14)(\mathrm{q} 25 ; \mathrm{q} 32) ; \mathrm{t}(3 ; 14)(\mathrm{p} 25 ; \mathrm{q} 32) ; \mathrm{t}$ $(6 ; 14)(\mathrm{q} 25 ; \mathrm{q} 32) ; \mathrm{t}(9 ; 14)(\mathrm{p} 13 ; \mathrm{q} 32) ; \mathrm{t}(9 ; 14)(\mathrm{q} 13 ; \mathrm{q} 32)$; and $\mathrm{t}$ $(14 ; 19)(\mathrm{q} 32 ; \mathrm{q} 13)$.

\section{Prognoses according to the chromosomal abnormalities and BM histology}

We analyzed the prognostic impacts of chromosomal abnormalities according to the complexity of the chromosomal aberrations involved (Figure 2). There was a significant difference in prognosis between patients with $\geq 2$ 


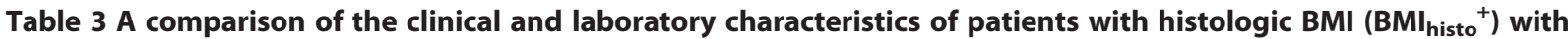
normal karyotypes and patients with chromosomal abnormalities

\begin{tabular}{|c|c|c|c|c|}
\hline \multirow[t]{2}{*}{ Parameters } & \multirow{2}{*}{$\begin{array}{l}\mathrm{BMI}_{\text {histo }}{ }^{+} \text {and normal karyotype } \\
\qquad(\mathrm{n}=135)\end{array}$} & \multicolumn{3}{|c|}{ Abnormal karyotypes } \\
\hline & & $\begin{array}{l}1 \text { numerical } \\
(n=42)\end{array}$ & $\begin{array}{l}1 \text { structural } \\
(n=12)\end{array}$ & $\begin{array}{c}\geq 2 \text { abnormalities } \\
(n=138)\end{array}$ \\
\hline \multicolumn{5}{|l|}{ Age (years) } \\
\hline Median (range) & $58(2-86)$ & $67(11-83)^{*}$ & $56(45-77)$ & $60(10-86)$ \\
\hline Age $>60 \mathrm{yr}$ & $64 / 135$ (47.4) & $34 / 42(81.0)^{*}$ & $5 / 12(41.7)$ & $66 / 138(47.8)$ \\
\hline Gender (male/female) & $59 / 76(43.7)$ & $35 / 7(83.3)^{*}$ & $10 / 2(83.3)^{*}$ & $76 / 62(55.1)$ \\
\hline$E C O G \geq 2$ & 26/135 (19.3) & $6 / 42(14.3)$ & $0 / 12(0)$ & $62 / 138(44.9)^{*}$ \\
\hline High serum LDH & 95/135 (70.4) & $16 / 42(38.1)^{*}$ & $6 / 12(50.0)$ & $123 / 138(89.1)^{*}$ \\
\hline B symptoms & 50/135 (37.0) & $7 / 42(16.7)^{*}$ & $6 / 12(50.0)$ & $98 / 138(71.0)^{*}$ \\
\hline Stage 3 or 4 & 123/135 (91.1) & $18 / 42(42.9)^{*}$ & $9 / 12(75.0)$ & 126/138 (91.3) \\
\hline \multicolumn{5}{|l|}{ excluding BM status } \\
\hline Extranodal $\geq 2$ sites & $89 / 135(65.9)$ & $13 / 42(31.0)^{*}$ & $5 / 12(41.7)$ & $112 / 138(81.2)^{*}$ \\
\hline \multicolumn{5}{|l|}{ IPI risk } \\
\hline Low & 0/135 (0) & 16/42 (38.1) & $1 / 12(8.3)$ & $1 / 138(0.7)$ \\
\hline Low/intermediate & 28/135 (20.7) & 10/42 (23.8) & $5 / 12(41.7)$ & 4/138 (2.9) \\
\hline High/intermediate & $65 / 135(48.2)$ & 10/42 (23.8) & $6 / 12(50.0)$ & $58 / 138(42.0)$ \\
\hline High & $42 / 135(31.1)$ & $6 / 42(14.3)^{*}$ & $0 / 12(0)^{*}$ & $75 / 138(54.4)^{*}$ \\
\hline Non-GCB type & $46 / 73(63.0)$ & $17 / 26(65.4)$ & $3 / 8(37.5)$ & $53 / 88(60.2)$ \\
\hline CD5- positive & $4 / 32(12.5)$ & $0 / 3(0)$ & $0 / 1(0)$ & $3 / 30(10.0)$ \\
\hline $\mathrm{R}-\mathrm{CHOP}$ treatment & $83 / 135(61.5)$ & $31 / 42(73.8)$ & $8 / 12(66.7)$ & 78/138 (56.5) \\
\hline Death & 53/135 (39.3) & 10/42 (23.8) & $2 / 12(16.7)$ & $90 / 138(65.2)^{*}$ \\
\hline
\end{tabular}

${ }^{*}$ Significant $P$ value $(<0.05)$ for each subgroup compared with the group of $\mathrm{BMI}_{\text {histo }}{ }^{+}$patients with normal karyotypes.

The data represent the number (percentage) for categorical variables, unless otherwise indicated.

Abbreviations: DLBCL, diffuse large B-cell lymphoma; ECOG, Eastern Cooperative Oncology Group; GCB, germinal center B-cell-like; IPI, International Prognostic Index; $\mathrm{LDH}$, lactic dehydrogenase; R-CHOP, rituximab, cyclophosphamide, doxorubicin, vincristine, and prednisolone.

abnormalities and those with a normal karyotype or a single abnormality both in the $\mathrm{BMI}_{\text {histo }}{ }^{+}$group (5-year OS, $22.0 \%$ vs. $52.7 \% ; P<0.001)$ and $\mathrm{BMI}_{\text {histo }}{ }^{-}$group $(5$-year $\mathrm{OS}, 31.8 \%$ vs. $66.5 \% ; P<0.001)$. In $\mathrm{BMI}_{\text {histo }}{ }^{-}$groups, the patients with a single numerical abnormality and those with single structural abnormality did not exhibit significant differences in OS compared with those with normal karyotypes $(P=0.422$ and 0.137 , respectively). The number of $\mathrm{BMI}_{\text {histo }}{ }^{+}$patients with single abnormalities was too small to assess prognostic impact (Additional file 2: Figure S1).

Table 4 A comparison of conventional cytogenetic (CG) and fluorescence in situ hybridization (FISH) results

\begin{tabular}{|c|c|c|c|c|c|c|c|c|c|c|}
\hline \multirow[b]{2}{*}{ Probe } & \multicolumn{5}{|c|}{ FISH positve } & \multicolumn{5}{|c|}{ FISH negative } \\
\hline & $\begin{array}{c}\text { No. of } \\
\text { patients }\end{array}$ & $\begin{array}{c}\mathrm{BMI}_{\text {histo }}^{+} / \\
\mathrm{CG}_{\text {whole }}{ }^{+}\end{array}$ & $\begin{array}{c}\mathrm{BMI}_{\text {histo }}^{+} / \\
\mathrm{CG}_{\text {whole }}{ }^{-}\end{array}$ & $\begin{array}{c}\mathrm{BMI}_{\text {histo }}{ }^{-} / \\
\mathrm{CG}_{\text {whole }}{ }^{+}\end{array}$ & $\begin{array}{c}\mathrm{BMI}_{\text {histo }}^{-} / \\
\mathrm{CG}_{\text {whole }}{ }^{-}\end{array}$ & $\begin{array}{c}\text { No. of } \\
\text { patients }\end{array}$ & $\begin{array}{c}\mathrm{BMI}_{\text {histo }}{ }^{+} / \\
\mathrm{CG}_{\text {locus }}{ }^{+}\end{array}$ & $\begin{array}{c}\mathrm{BMI}_{\text {histo }}{ }^{+} / \\
\mathrm{CG}_{\text {locus }}{ }^{-}\end{array}$ & $\begin{array}{c}\mathrm{BMI}_{\text {histo }}^{-} / \\
\mathrm{CG}_{\text {locus }}{ }^{+}\end{array}$ & $\begin{array}{c}\mathrm{BMI}_{\text {histo }}{ }^{-} / \\
\mathrm{CG}_{\text {locus }}{ }^{-}\end{array}$ \\
\hline $14 q 32 / / G H$ & $37 / 235(15.7)$ & $20(54.1)$ & $11(29.7)$ & $3(8.1)$ & $3(8.1)$ & 198/235 (84.3) & $6(3.0)$ & $54(27.3)$ & $0(0.0)$ & $138(69.7)$ \\
\hline $9 p 21 / p 16$ & 17/178 (9.6) & $14(82.4)$ & $3(17.6)$ & $0(0)$ & $0(0)$ & $161 / 178(90.4)$ & $3(1.9)$ & $50(31.1)$ & $0(0)$ & $108(67.1)$ \\
\hline $3 q 27 / B C L 6$ & 19/95 (20.0) & $14(73.7)$ & $5(26.3)$ & $0(0)$ & $0(0)$ & 76/95 (80.0) & $2(2.6)$ & $28(36.8)$ & $0(0)$ & $46(60.5)$ \\
\hline $8 q 24 / M Y C$ & $7 / 50(14.0)$ & $5(71.4)$ & $2(28.6)$ & $0(0)$ & $0(0)$ & $43 / 50(86.0)$ & $3(7.0)$ & $12(27.9)$ & $1(2.3)$ & $27(67.8)$ \\
\hline $1 p 32 / 1 q 25$ & $9 / 49(18.4)$ & $9(100)$ & $0(0)$ & $0(0)$ & $0(0)$ & $40 / 49(81.6)$ & $1(2.5)$ & $21(52.5)$ & $0(0)$ & $18(45.0)$ \\
\hline 17p13/TP53 & $3 / 34(8.8)$ & $1(33.3)$ & $2(66.7)$ & $0(0)$ & $0(0)$ & $31 / 34(91.2)$ & $0(0)$ & $8(25.8)$ & $0(0)$ & $23(74.2)$ \\
\hline $18 q 23 / B C L 2$ & $3 / 29(10.3)$ & $0(0)$ & $2(66.7)$ & $1(33.3)$ & $0(0)$ & $26 / 29(89.7)$ & $2(7.7)$ & $7(26.9)$ & $0(0)$ & $17(65.4)$ \\
\hline
\end{tabular}

The data represent the number (percentage) for categorical variables.

Abbreviations: $\mathrm{FISH}$, fluorescence in situ hybridization; $\mathrm{CG}_{\text {whole }}{ }^{+} / \mathrm{CG}_{\text {whole }}{ }^{-}$, normal or abnormal results of conventional cytogenetic tests considering whole chromosomes; $\mathrm{CG}_{\text {locus }}{ }^{+} / \mathrm{CG}_{\text {locus }}{ }^{-}$, normal or abnormal results of conventional cytogenetic tests for the specific locus, which is targeted by FISH probes. 


\section{A}
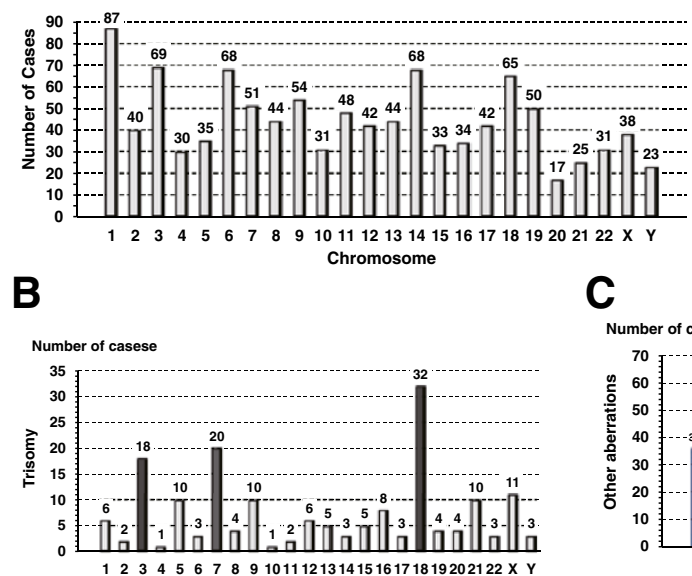

Number of casese

${ }^{0}$ : Пएवा

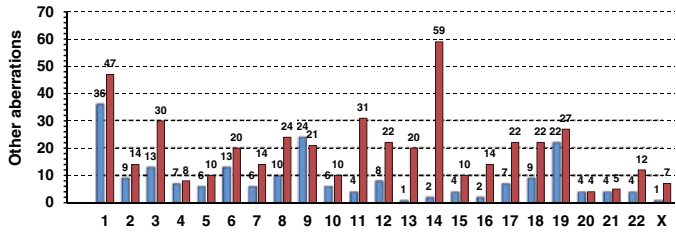

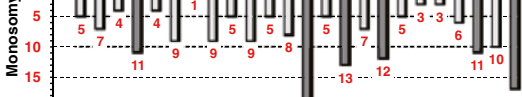

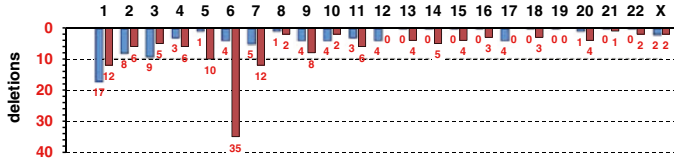

D
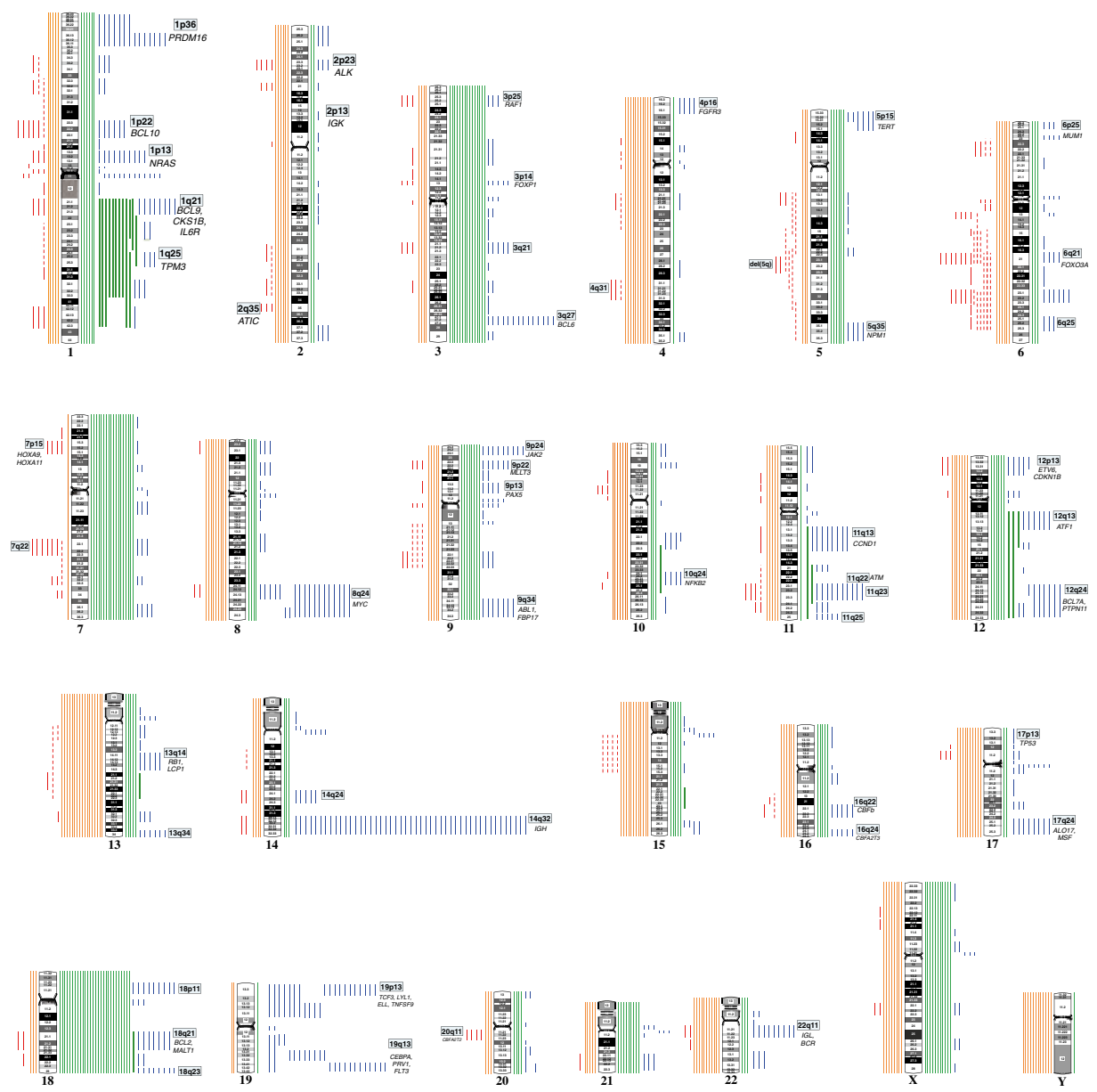

Figure 1 (See legend on next page.) 
(See figure on previous page.)

Figure 1 Chromosomal aberrations in patients with chromosomal aberrations except single numerical aberrations $(n=150)$. (A) The frequency of the chromosomes involved. (B) The frequencies of chromosomal gains (upper bars) and losses (lower bars). (C) The frequencies of structural aberrations in each chromosome arm ( $p$ arm, blue; q arm, red). (D) Ideograms showing the specific chromosomal aberrations. The orange lines on the left of the ideogram indicate chromosomal losses, and the green lines on the right side indicate gains. The red lines represent breakage points of deletions, and the blue lines indicate breakage points of chromosomal rearrangements. The thick green lines represent duplications.

There was no significant difference in OS and PFS according to the number of abnormalities among the patients with $\geq 2$ abnormalities (Additional file 3: Figure S2).

When patients were classified according to IPI risk groups, $\mathrm{BMI}_{\text {histo }}{ }^{+}$patients with $\geq 2$ cytogenetic abnormalities presented significantly poorer prognosis compared with normal karyotypes in the high/intermediate-risk group (5-year OS, $35.4 \%$ vs. $69.4 \%, P<0.001$; Figure $3 \mathrm{~A}$ ). $\mathrm{BMI}_{\text {histo }}{ }^{-}$patients with $\geq 2$ abnormalities revealed significantly poorer prognosis in the high/intermediate and high risk groups (5-year OS, $31.8 \%$ vs. $58.4 \%, P=0.027$ for high/intermediate risk group; $0 \%$ vs. $40.6 \%, P<0.001$ for high risk group, respectively; Figure 3B).

When R-CHOP-treated patients were analyzed separately, $\geq 2$ chromosomal abnormalities were associated with poorer prognoses compared with normal karyotypes or 1 abnormality among both the R-CHOP-treated $\mathrm{BMI}_{\text {histo }}{ }^{+}$patients (5-year OS, $33.9 \%$ vs. $70.9 \% ; P<0.001$ ) xand the $\mathrm{BMI}_{\text {histo }}{ }^{-}$patients (5-year OS, $39.5 \%$ vs. $72.2 \%$; $P=0.003$; Additional file 4: Figure S3).
The presence of a monosomal karyotype had no apparent prognostic value among patients with $\geq 2$ abnormalities (5-year OS, $25.4 \%$ vs. $20.0 \% ; P=0.274$ ). There was no significant prognostic value of hyperdiploidy among patients with $\geq 2$ abnormalities (5-year OS, $24.7 \%$ vs. $23.1 \%$; $P=$ 0.413). Among the 877 patients for whom IHC information was available, the non-GCB group demonstrated a lower OS than the GCB group (5-year OS, $58.6 \%$ vs. $71.2 \%$, respectively; $P=0.004$ ). However, among patients with $\geq 2$ abnormalities, there was no significant difference in OS between the non-GCB and GCB types (5-year OS, 25.4\% vs. $23.4 \%$, respectively; $P=0.467$ ).

Prognoses according to specific chromosomal abnormalities We investigated the prognostic impacts of the specific chromosomal abnormalities. Figure 4A presents hazard ratios (HRs) obtained by univariate Cox analysis for OS and PFS according to specific chromosomal abnormalities found in $\geq 8$ patients using $\mathrm{BMI}_{\text {histo }}{ }^{+}$patients with normal karyotype as a reference group among 327

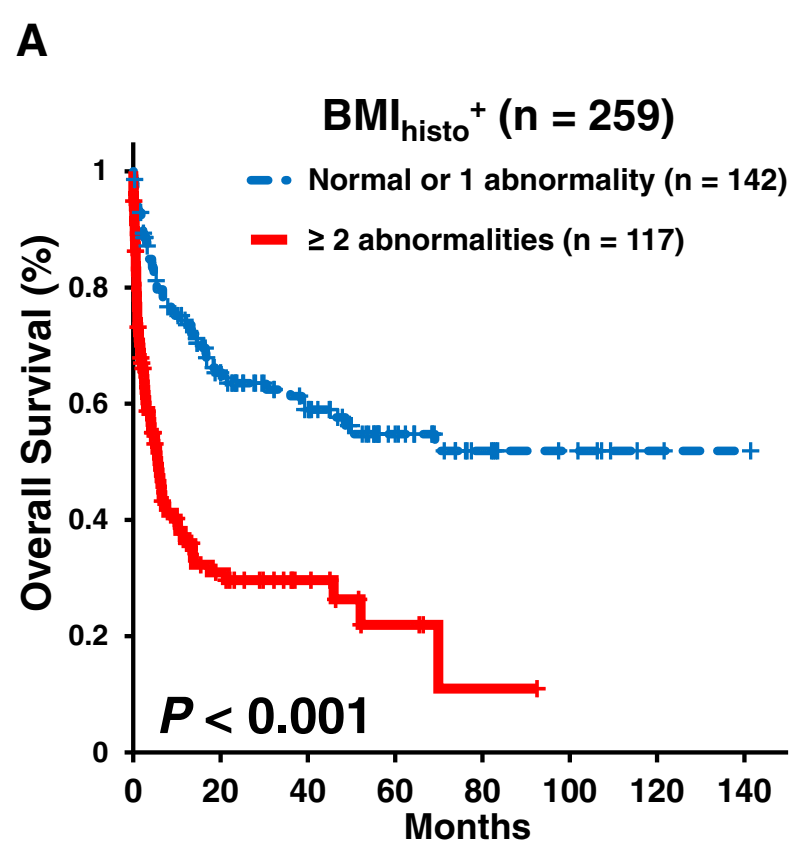

B

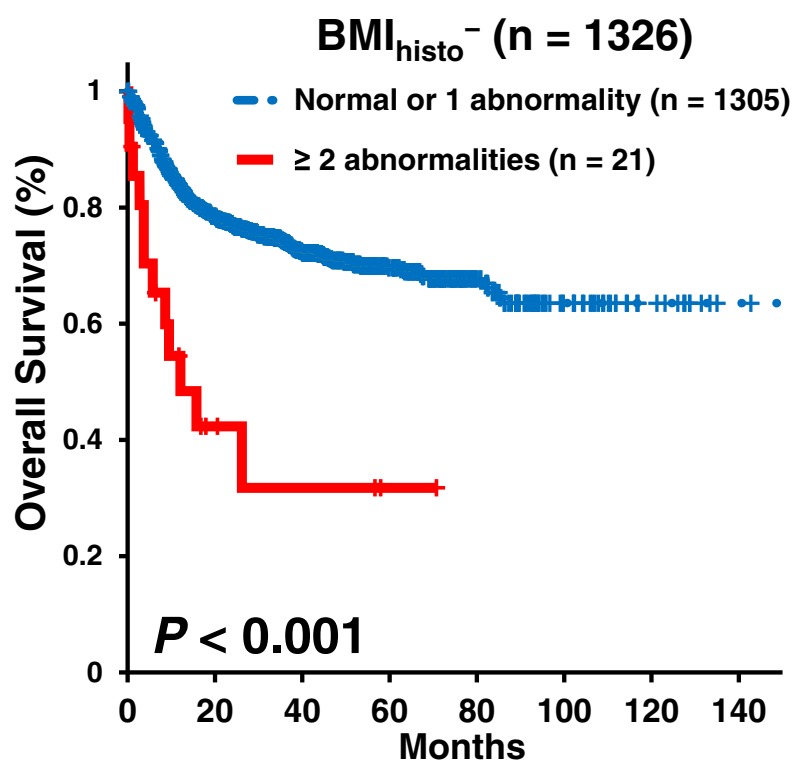

Figure 2 Overall survival (OS) according to the chromosomal abnormalities and BM histology. (A) Kaplan Meier survival curves for patients with histologic bone marrow involvement $\left(\mathrm{BMI}_{\text {histo }}{ }^{+} ; \mathrm{n}=259\right)$ and $\mathbf{( B )}$ for patients without histologic bone marrow involvement $\left(\mathrm{BMI}_{\text {histo }}{ }^{-}\right.$; $\mathrm{n}=1326$ ). The patients with $\geq 2$ chromosomal abnormalities exhibited significantly worse survival in both the $\mathrm{BMI}_{\text {histo }}{ }^{+}$and $\mathrm{BMI}_{\text {histo }}{ }^{-}$groups. 

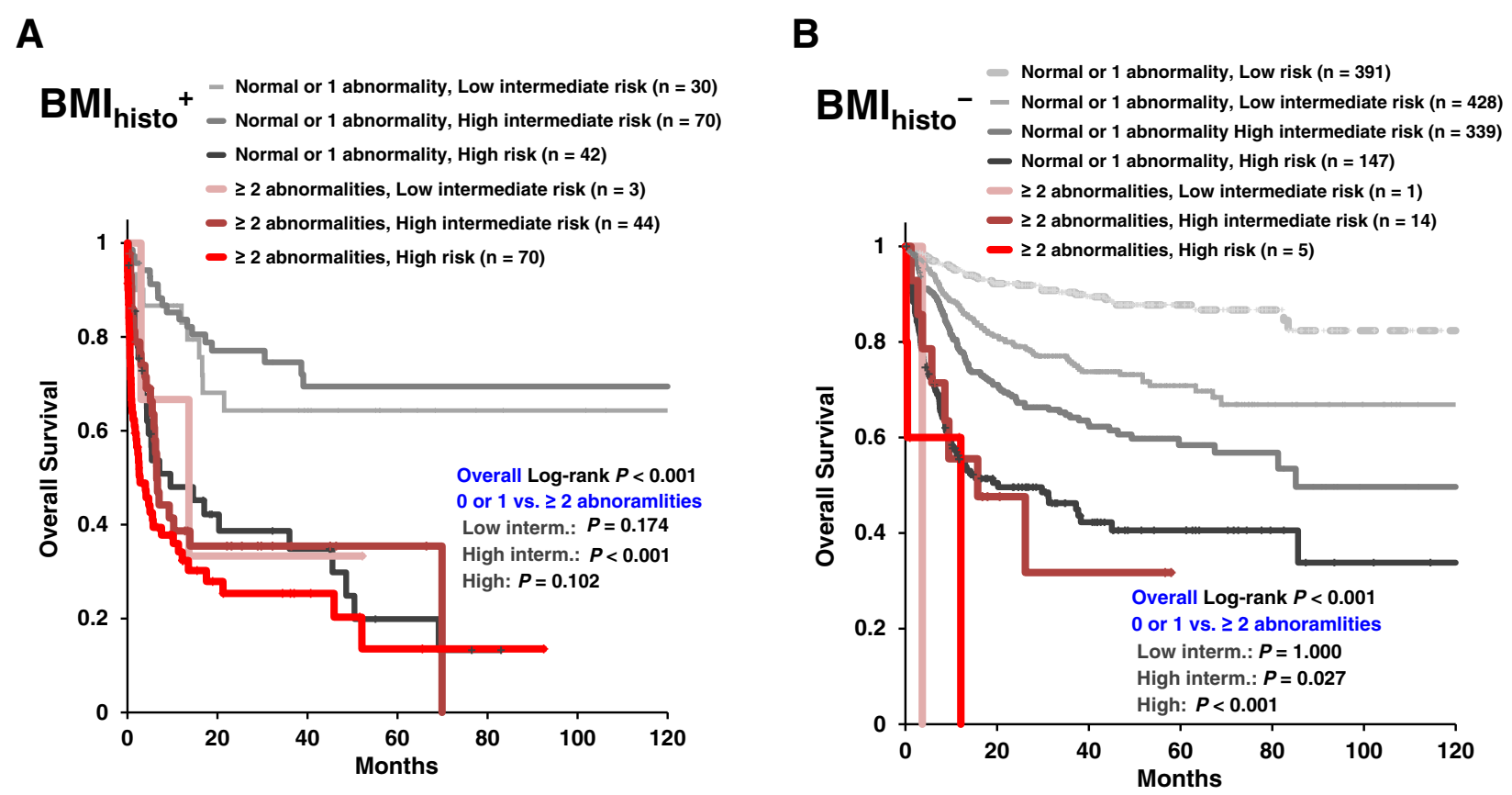

Figure 3 Overall survival (OS) according to risk stratification by international prognostic index (IPI) scores and chromosomal abnormalities. (A) Kaplan Meier survival curves for patients with histologic bone marrow involvement $\left(\mathrm{BMI}_{\text {histo }}{ }^{+} ; \mathrm{n}=259\right)$ and (B) for patients without histologic bone marrow involvement $\left(\mathrm{BMI}_{\text {histo }}{ }^{-} ; \mathrm{n}=1326\right)$.

patients with either cytogenetic abnormalities or were $\mathrm{BMI}_{\text {histo }}{ }^{+}$. The presence of structural abnormalities at 16q22-q24 was significantly associated with a higher risk for both OS (HR, 5.86, $P<0.001)$ and disease progression (HR, 4.05, $P<0.001)$. The abnormalities at $6 \mathrm{p} 21$ (HR for OS, 4.89, $P<0.001), 12 \mathrm{q} 22-\mathrm{q} 24$ (HR, 4.28, $P<0.001)$, and -17 (HR, 4.49, $P<0.001)$ were also significant association with adverse prognosis. Consistent results were observed in the R-CHOP-treated patients (Additional file 5: Figure S4). In addition, frequent loci of cytogenetic abnormalities, including 11q21-q23, 19q13, 18q21, 1q21-q23, 8q24, 19p13, 3q27, 6q, and 14q32 were also associated with adverse outcomes.

To identify the subgroups of BM-involved DLBCL that exhibited distinct cytogenetic aberrations, we performed cluster analyses using the loci associated with poor survival in the univariate analysis and frequent and characteristic breakpoints, including 14q32, 3q27, 8q24, 19p13, and $19 \mathrm{p} 13$. Based on the hierarchical cluster analysis, 138 patients with $\geq 2$ chromosomal abnormalities were segregated into clusters with characteristic patterns of chromosomal abnormalities (Figure 4B). When we compared prognoses among the clusters, Cluster 7, which was composed of loci associated with poorer prognoses in the univariate analysis, revealed the poorest prognosis (Figure 4C).
Multivariate analysis of prognoses among patients with BM abnormalities diagnosed by either histologic examination or conventional cytogenetic testing A multivariate analysis was performed for 327 patients who had either chromosomal abnormalities or were $\mathrm{BMI}_{\text {histo }}{ }^{+}$(Table 5). When the presence of $\geq 2$ cytogenetic abnormalities was analyzed with other covariates, the presence of $\geq 2$ cytogenetic abnormalities was also significantly associated with a worse OS (HR, 2.49; 95\% CI, 1.75-3.54; $P<0.001)$. The high IPI score was strongly associated with a poor prognosis, whereas R-CHOP treatment was strongly associated with a better prognosis. When the specific chromosomal abnormalities which were associated with adverse prognosis in the univariate analysis were analyzed, the aberration at $19 \mathrm{p} 13$ was selected as an independent adverse prognostic factor (HR, 2.67; 95\% CI, 1.50-4.76; $P=0.001$ ), in addition to $7 \mathrm{q} 22$, $12 q 22-q 24,18 q 21$, and 16q22-q24. When PFS was analyzed, aberrations at $19 \mathrm{p} 13$ and $8 \mathrm{q} 24$ emerged as factors independently associated with disease progression (HR, 3.02 and 2.61, respectively; $P<0.001$ and $P<0.001$, respectively). When $200 \mathrm{R}-\mathrm{CHOP}$ treated patients among 327 patients were analyzed separately, 19q13 (HR, 3.36, $P=0.003), 12 \mathrm{q} 22-\mathrm{q} 24,19 \mathrm{p} 13$, and $8 \mathrm{q} 24$ were independently predicted poor OS, and $19 \mathrm{p} 13$ and $8 \mathrm{q} 24$ were associated with disease progression (Table 5). 
A

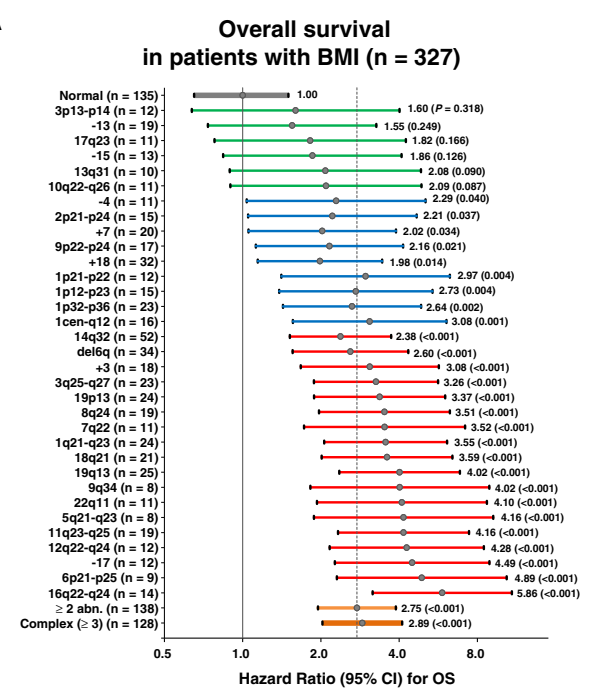

B

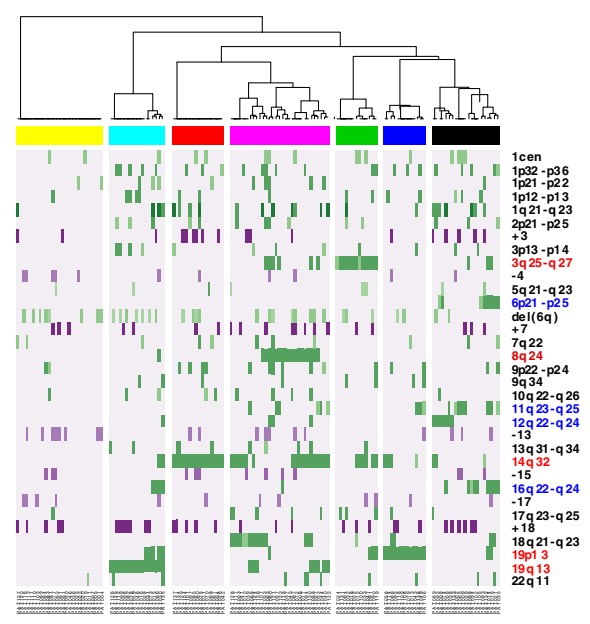

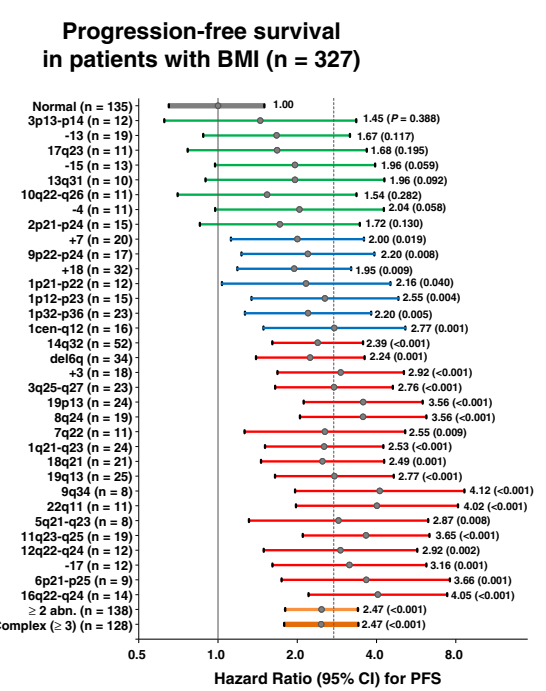

C
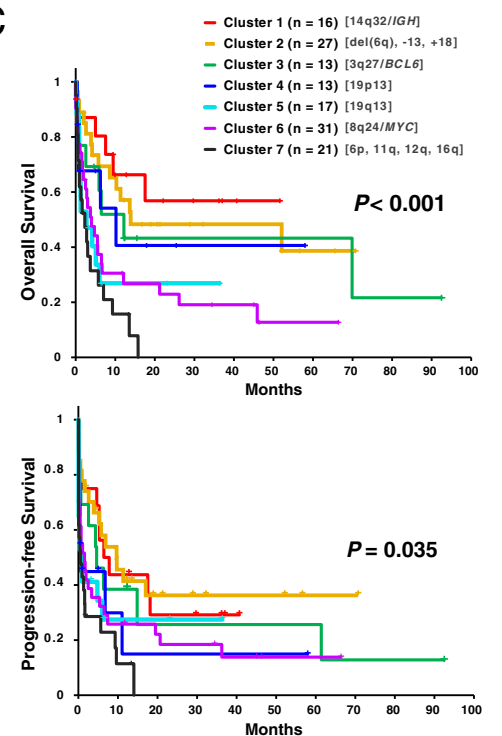

Figure 4 Prognoses according to specific chromosomal abnormalities. (A) Forest plots showing hazard ratios obtained by univariate Cox analysis for overall survival (OS) and progression-free survival (PFS) according to the presence of specific chromosomal abnormalities using patients with lymphoma bone marrow involvement and normal karyotype as a reference group in 327 patients having either abnormal karyotypes or histologic BM involvement. (B) Based on a cluster analysis of 33 frequent numerical abnormalities and breakpoints, 138 patients with $\geq 2$ chromosomal abnormalities were segregated into clusters with characteristic abnormality patterns. The horizontal labels indicate clusters (red, Cluster 1; yellow, Cluster 2; green, Cluster 3; blue, Cluster 4; cyan, Cluster 5; purple, Cluster 6; and black, Cluster 7). The characteristic loci of the abnormalities in each cluster are indicated in red, and the loci associated with a poor prognosis in the univariate analysis are indicated in blue in the right panel. (C) The (OS) and PFS of each cluster is plotted.

\section{Discussion}

With recent advances in genetic technology, the value of G-banding data is often underestimated compared with the data derived from higher-resolution techniques, such as $\mathrm{FISH}$, array-CGH, and deep sequencing. Molecular testing for immunoglobulin gene rearrangements is also a sensitive test for detecting clonal cells within bone marrow, which detected BM positive cases in $16 \%$ of histologically negative cases in a previous study $[6,19]$. Although conventional karyotyping has low resolution, this method remains the only technique used worldwide in many hospital laboratories; thus, it is readily applicable in routine practice. In addition, the advantages of conventional cytogenetic tests include their ability to detect abnormalities in proliferative clones; to provide information regarding whole chromosomes, including balanced translocations; and to distinguish between heterogeneous clones that coexist in a sample.

In fact, conventional cytogenetic testing is not as widely performed for DLBCL as for other hematologic 
Table 5 Multivariate Cox analysis of the overall survival (OS) and progression-free survival (PFS) among 327 patients having either cytogenetic abnormalities (CAs) or histologic $\mathrm{BM}$ involvement $\left(\mathrm{BMI}_{\text {histo }}{ }^{+}\right)$and among $\mathrm{R}$-CHOP treated patients $(n=200)^{*}$

\begin{tabular}{|c|c|c|c|c|c|c|c|}
\hline \multirow[b]{2}{*}{ Risk factors } & \multirow[b]{2}{*}{ No. of patients (\%) } & \multicolumn{3}{|c|}{ OS } & \multicolumn{3}{|c|}{ PFS } \\
\hline & & HR & $95 \% \mathrm{Cl}$ & $P$ & HR & $95 \% \mathrm{Cl}$ & $P$ \\
\hline \multicolumn{8}{|l|}{ Total patients with CAs and/or $\mathrm{BMI}_{\text {histo }}{ }^{+}(\mathrm{n}=327)$} \\
\hline \multicolumn{8}{|l|}{ Presence of $\geq 2$ cytogenetic abnormalities as a risk factor } \\
\hline IPI risk group, high vs. low & $123(37.6)$ & 6.46 & $1.56-26.72$ & 0.010 & 7.15 & $1.73-29.46$ & 0.007 \\
\hline R-CHOP treatment, R-CHOP vs. others & $200(61.2)$ & 0.26 & $0.18-0.35$ & $<0.001$ & 0.38 & $0.28-0.51$ & $<0.001$ \\
\hline$\geq 2$ cytogenetic abnormalities vs. 0 or 1 abnormality & $138(42.2)$ & 2.49 & $1.75-3.54$ & $<0.001$ & 2.12 & $1.53-2.93$ & $<0.001$ \\
\hline \multicolumn{8}{|l|}{ Presence of specific cytogenetic abnormalities as risk factors } \\
\hline IPI risk group, high vs. low & $123(37.6)$ & 8.34 & $2.04-24.09$ & 0.003 & 8.43 & $2.06-34.44$ & 0.003 \\
\hline R-CHOP treatment, R-CHOP vs. others & $200(61.2)$ & 0.24 & $0.17-0.34$ & $<0.001$ & 0.32 & $0.24-0.44$ & $<0.001$ \\
\hline $19 p 13$ abnormality present vs. absent & $24(7.3)$ & 2.67 & $1.50-4.76$ & 0.001 & 3.02 & $1.85-4.93$ & $<0.001$ \\
\hline 7q22 abnormality present vs. absent & $11(3.4)$ & 3.03 & 1.51.-6.06 & 0.002 & NS & NS & NS \\
\hline 12q22-q24 abnormality present vs. absent & $12(3.7)$ & 2.68 & 1.37.-5.26 & 0.004 & NS & NS & NS \\
\hline 18 q21 abnormality present vs. absent & $21(6.4)$ & 2.11 & 1.22.-3.64 & 0.007 & NS & NS & NS \\
\hline 16q22-q24 abnormality present vs. absent & $14(4.3)$ & 2.27 & $1.23-4.18$ & 0.009 & NS & NS & NS \\
\hline 11q23-q25 abnormality present vs. absent & $19(5.8)$ & 1.81 & $1.03-3.15$ & 0.038 & NS & NS & NS \\
\hline $8 q 24$ abnormality present vs. absent & $19(5.8)$ & NS & NS & NS & 2.61 & $1.54-4.43$ & $<0.001$ \\
\hline \multicolumn{8}{|c|}{$\mathrm{R}-\mathrm{CHOP}$ treated patients with CAs and/or $\mathrm{BMI}_{\text {histo }}{ }^{+}(\mathrm{n}=200)$} \\
\hline \multicolumn{8}{|l|}{ Presence of $\geq 2$ cytogenetic abnormalities as a risk factor } \\
\hline IPI risk group, high vs. low & $67(33.5)$ & 5.29 & $1.23-22.86$ & 0.026 & 5.55 & $1.32-23.37$ & 0.020 \\
\hline Male vs. female & $112(56.0)$ & 1.71 & $1.01-2.91$ & 0.046 & NS & NS & NS \\
\hline$\geq 2$ cytogenetic abnormalities vs. 0 or 1 abnormality & $78(39.0)$ & 2.01 & $1.17-3.45$ & 0.012 & 2.15 & $1.38-3.38$ & 0.001 \\
\hline \multicolumn{8}{|l|}{ Presence of specific cytogenetic abnormalities as risk factors } \\
\hline IPI risk group, high vs. low & $67(33.5)$ & 5.92 & $1.40-25.04$ & 0.016 & 7.61 & $1.82-31.92$ & 0.006 \\
\hline Male vs. female & $112(56.0)$ & 2.00 & $1.15-3.47$ & 0.014 & 1.71 & $1.09-2.69$ & 0.021 \\
\hline $19 q 13$ abnormality present vs. absent & $13(6.5)$ & 3.36 & $1.50-7.54$ & 0.003 & NS & NS & NS \\
\hline 12q22-q24 abnormality present vs. absent & $6(3.0)$ & 3.65 & $1.42-9.44$ & 0.007 & NS & NS & NS \\
\hline $19 p 13$ abnormality present vs. absent & $16(8.0)$ & 2.85 & $1.20-6.80$ & 0.018 & 3.31 & $1.68-6.51$ & 0.001 \\
\hline $8 \mathrm{q} 24$ abnormality present vs. absent & $13(6.5)$ & 2.54 & $1.24-5.23$ & 0.011 & 2.43 & $1.24-4.73$ & 0.009 \\
\hline
\end{tabular}

*The multivariate Cox regression models initially included age, gender, the International Prognostic Index (IPI) risk groups, history of R-CHOP treatment, presence of histologic bone marrow involvement, and either presence of $\geq 2$ cytogenetic abnormalities, or presence of specific cytogenetic abnormalities found in minimum $5 \mathrm{R}$ CHOP-treated patients and associated with significant poor prosnosis in the univariate analysis $(+3,-17$, abnormalities at 14q32, 3q25-q27, 19p13, 8q24, 7q22, 1q21-q23, $18 q 21,19 q 13,9 q 34,22 q 11,11 q 23-q 25,12 q 22-q 24,16 q 22-q 24$, and deletion $6 q)$. The stepwise selection procedure was used to select variables in the final models. Abbreviations: $\mathrm{Cl}$, confidence interval; $\mathrm{HR}$, hazard ratio; NS, not significant.

malignancies, such as acute leukemia and multiple myeloma. The disadvantages of cytogenetic testing using tissue samples include the necessity of laborious tissue preparation, the presence of fuzzy chromosomes, a lack of metaphase cells, and contamination. Because BM studies are a standard process of DLBCL staging, the use of BM samples for additional conventional cytogenetic testing is easily applicable. There are two major possible advantages associated with the cytogenetic testing of BM samples in DLBCL patients: an increased sensitivity for detecting BM involvement in DLBCL and the information provided by the chromosomal abnormalities found in the BM. In this study, we analyzed retrospective data from a large series of patients to analyze both possible advantages.

One major difficulty in the decision about whether to perform cytogenetic testing on BM specimens is caused by the absence of BM involvement in many DLBCL patients. Even in patients with BM involvement, the lymphoma cells may be obscured by the more abundant normal hematopoietic cells $[5,6,19,20]$. In our data, $8.8 \%$ of the total patients exhibited multiple chromosomal abnormalities, and $1.3 \%$ of the patients were diagnosed with $\mathrm{BM}$ involvement on the basis of cytogenetic results 
alone. Considering that $16.3 \%$ of the cases in our study were $\mathrm{BMI}_{\text {histo }}{ }^{+}$, the detection rate of significant cytogenetic abnormalities in BM specimens was not negligible. Because karyotyping is based on metaphases, the number of metaphases with cytogenetic abnormalities does not necessarily represent the proportion of cells within BM cells [21]. Karyotyping may be a sensitive method, because a small clone with proliferative advantage over normal cells may be identified by karyotyping.

The interpretation of data from patients with a single abnormality can be difficult because the abnormality does not necessarily originate from lymphoma cells. In our study, single aneuploidies demonstrated only a $10 \%$ concordance rate with histologic examination, which indicates that a single aneuploidy cannot be the definite evidence for presence of lymphoma cells. In addition, patients with single aneuploidies had less aggressive disease than normal karyotype cases with histologic involvement and presented no significant differences in prognosis. Therefore, the presence of a single numerical abnormality cannot be an indicator of the advanced disease and a poor prognostic factor. In fact, loss of chromosome $Y$ is a well-known normal age-related phenomenon in elderly males [22]. Although monosomy 21 can be detected as a sole cytogenetic abnormality in a variety of hematologic disorders, the random loss of chromosome as an artifact of cell culture or slide preparation can cause this abnormality [23]. Single structural abnormalities also presented lower concordance rate with histologic BM involvement. There were 2 patients with del(20q) without histologic evidence of $\mathrm{BM}$ involvement. Although these patients did not presented cytopenia or morphologic dysplasia, previous studies reported that myelodysplastic syndrome associated with isolated del(20q) can commonly present with minimal morphological dysplasia [24]. There were a patient with duplication of $\mathrm{Y}$ chromosome and patients with balanced translocation, which may be constitutional chromosomal aberrations [25,26]. However, some single abnormalities can represent a primary event in lymphomagenesis. In this study, single structural abnormalities such as $\mathrm{t}(14 ; 18)$ (q32; $\mathrm{q} 21)$ or $\mathrm{t}(3 ; 14)(\mathrm{q} 27 ; \mathrm{q} 32)$ can be reasonably regarded as originated from lymphoma cells considering their well-known chromosomal loci and their concordant histologic BM results. Because of the small number of analyzed cases, it was hard to make convincing conclusion about the significance and prognostic impact of these single abnormalities in this study. When these abnormalities are detected, cautious BM examination with other ancillary tests may be needed. Further studies will be needed for more clear conclusion and to make a guideline on the appropriate interpretation of ambiguous cytogenetic abnormalities.

Most importantly, this study demonstrated that BM cytogenetic results have a powerful prognostic significance that is independent of BM histology. The presence of $\geq 2$ chromosomal abnormalities was associated with very poor prognosis among both patients with and without histologic BM involvement. This finding confirms that a BM cytogenetic result is a stronger prognostic predictor than histologic BM involvement. The significant prognostic effect of cytogenetic abnormalities was observed in patients that had been stratified according to their IPI risk scores, especially for patients with high intermediate risks.

The chromosomal abnormalities observed in this study were nonrandom and recurrent, implying that they may belong to the recurrent lymphomagenesis pathway [27]. There have been previous reports of high frequencies of many of these abnormalities, including rearrangements at 14q32, 1p, 3q27, 8q24, 11q23-q25, and 18q21-q23; duplications at 1q; and deletions at $6 \mathrm{q}$. The most common numerical abnormality in DLBCL, trisomy 18 , has also been frequently reported in many other B-cell neoplasms $[28,29]$. The $14 \mathrm{q} 32 / I G H$ rearrangement, which was the single most common abnormality in the present study, is frequently observed in all B-cell neoplasia [30-36]. Because $14 \mathrm{q} 32 / \mathrm{IGH}$ rearrangements mainly involve balanced translocations, these rearrangements can be detected only by G-banding, not through array methods [37-41].

In our data from patients with multiple abnormalities, which specific loci presented abnormalities was a more significant prognostic factor than the number of abnormalities. Several abnormalities, including aberrations at 16q22-q24, 6p21-p25, 12q22-q24, 11q23-q25, 19q13, $1 \mathrm{q} 21-\mathrm{q} 23,8 \mathrm{q} 24$, and $19 \mathrm{p} 13$, and -17 appeared to be associated with a worse prognosis in the univariate analysis. The multivariate analysis demonstrated that several chromosomal abnormalities including aberrations at 19p13, 7q22, 12q22-q24, 18q21, and 16q22-q24 are independent adverse prognostic factors for survival among DLBCL patients with BM involvement. In addition, abnormalities at 19q13, 12q22-q24, 19p13, and 8q24 were associated with poor prognoses among R-CHOP treated patients with BM abnormalities. Because of the small number of patients having each specific cytogenetic abnormality, and the high variability of the cytogenetic abnormalities, to make clear conclusion about the prognostic importance of each specific chromosomal loci might be difficult. However, we considered a recurrent cytogenetic abnormality with a high statistical significance, such as abnormalities at $19 \mathrm{p} 13$ can be a potentially important target for further investigation. Aberrations in chromosome 19 have been reported in several previous series of DLBCL cases, although their prognostic impact was not explored [30,33,35,36,40-42]. The identity of the specific gene on 19p13 that is associated with DLBCL is not yet known; however, TCF3 has been reported to be associated with acute lymphoblastic leukemia [43], and microRNA (miRNA) genes have been 
implicated in mature B-cell neoplasia [44]. In addition, a recent study using array-CGH and SNP-chip analyses reported that recurrent deletions of the tumor suppressor genes, TNFSF7 and TNFSF9 at the 19p13.3 region were observed in DLBCL and Burkitt lymphomas [45]. These genes may play an important role in the pathogenesis of DLBCL leading to disease progression and BM involvement. The $M Y C / 8 \mathrm{q} 24$ rearrangement, which has been reported to be associated with a poor prognosis when detected in tissues using FISH at the time of diagnosis [46-49], was independently associated with disease progression in this study. The nonrandom nature of the observed chromosomal abnormalities and their association with prognosis suggest that investigations into the clonal evolution of DLBCL could provide useful insights into the pathogenesis of this disease.

Our study has several limitations. First, this study was performed retrospectively, and the patients had undergone heterogeneous therapies. Second, the evaluations of the cell of origin and CD5 positivity were limited. Third, several BM-related prognostic factors, including the extent and histologic characteristics of the BM involvement, could not be investigated [3,4,50,51]. However, considering the comparable results of the $\mathrm{BMI}_{\text {histo }}{ }^{+}$and $\mathrm{BMI}_{\text {histo }}{ }^{-}$cases, it could be suggested that cytogenetic aberrations are a stronger prognostic factor than other BM-related factors.

The results of this study may be representative of the major characteristics of the BM chromosomal abnormalities in the Korean DLBCL population, considering the large size of our data series. A larger series of international investigations may be needed to characterize and confirm the prognostic significance of the BM cytogenetic aberrations in DLBCL patients from other ethnic groups, considering the variety of external genotoxic agents that can cause chromosomal changes and the diversity of host susceptibility factors to chromosomal breaks. Results from classic cytogenetics can guide the design of additional studies using other techniques, such as FISH or arrays.

In conclusion, the conventional cytogenetic testing of BM may provide essential information for newly diagnosed DLBCL patients. We suggest that cytogenetic testing of BM samples should be integrated with DLBCL staging apart from histologic examination, and more effective therapeutic strategies should be developed. In addition, frequently affected cytogenetic regions, such as 19 p13, must be intensively investigated to characterize the underlying molecular pathogenesis of DLBCL.

\section{Additional files}

Additional file 1: Table S1. Detailed karyotypes of 192 patients with chromosomal abnormalities. Karyotype results were classified according to the complexity of chromosomal abnormalities observed.
Additional file 2: Figure S1. Kaplan-Meier survival plots of OS according to histologic bone marrow involvement (BMI) and chromosomal abnormalities found in bone marrow cells in DLBCL patients. (A) The patients with a single abnormality did not exhibit significant differences in OS in patients without bone marrow involvement $\left(\mathrm{BMI}_{\text {histo }}{ }^{-}\right)$. (B) The patients with complex karyotypes ( $\geq 3$ abnormaliteis) exhibited significantly worse survival in both the $\mathrm{BMI}_{\text {histo }}{ }^{+}$and $\mathrm{BMI}_{\text {histo }}{ }^{-}$groups.

Additional file 3: Figure S2. Survival according to the total number of chromosomal abnormalities in 1585 DLBCL patients. (A) overall survival (OS). (B) progression-free survival (PFS). The patients with $\geq 2$ abnormalities exhibited significantly worse OS and PFS; however, there was no significant difference according to the number of abnormalities among patients with $\geq 2$ abnormalities.

Additional file 4: Figure S3. Kaplan-Meier survival plots of overall survival (OS) of R-CHOP treated DLBCL patients according to chromosomal abnormalities (A) in patients with histologic bone marrow involvement $\left(\mathrm{BMI}_{\text {histo }}{ }^{+}\right)$and (B) in patients without histologic bone marrow involvement ( $\left(\mathrm{BMI}_{\text {histo }}{ }^{-}\right)$. (C and $\left.\mathrm{D}\right) \mathrm{OS}$ according to risk stratification by international prognostic index (IPI) scores and chromosomal abnormalities (C) in R-CHOP-treated $\mathrm{BMI}_{\text {histo }}{ }^{+}$patients and (D) in R-CHOP-treated $\mathrm{BMI}_{\text {histo }}{ }^{-}$patients.

Additional file 5: Figure S4. Forest plots showing hazard ratios (HRs) obtained by univariate Cox analysis for (A) overall survival (OS) and (B) progression-free survival (PFS) according to the presence of specific chromosomal abnormalities using patients with lymphoma bone marrow involvement and normal karyotype as a reference group in R-CHOPtreated patients having either abnormal karyotypes or histologic BM involvement $(n=200)$.

\section{Competing interests}

The authors declare that they have no competing interests.

\section{Authors' contributions}

CS and DSL designed the study, SYK, HJK, HJK, JSK, HSE, TMK, SSY, CS, and DSL provided study materials or patients, collected and assembled data. SYK, CS, and DSL analyzed and interpreted data. SYK, HJK, HJK, JSK, HSE, TMK, SSY, $\mathrm{CS}$, and DSL wrote the manuscript. All authors have read and approved the final manuscript.

\section{Acknowledgments}

This work was supported by (1) the Basic Science Research Program through the National Research Foundation of Korea (NRF) Funded by the Ministry of Education, Science and Technology (2012-0002257), (2) a grant (10172KFDA993) from Korea Food \& Drug Administration, (3) a grant of the Korean Health Technology R\&D Project, Ministry of Health \& Welfare, Republic of Korea (A120216).

\section{Author details}

'Department of Laboratory Medicine, Seoul National University Hospital, Seoul National University College of Medicine, 101 Daehak-ro, Jongno-gu, Seoul 110-744, Republic of Korea. ${ }^{2}$ Department of Internal Medicine, Hallym University Sacred Heart Hospital, Hallym University College of Medicine, Anyang, Republic of Korea. ${ }^{3}$ Department of Internal Medicine, Korea Cancer Center Hospital, Korea Institute of Radiological and Medical Sciences, Seoul, Republic of Korea. ${ }^{4}$ Department of Internal Medicine, Severance Hospital, Yonsei University College of Medicine, Seoul, Republic of Korea.

${ }^{5}$ Hematology-Oncology Clinic, Research Institute and Hospital, National Cancer Center, Goyang, Republic of Korea. ${ }^{6}$ Department of Internal Medicine, Seoul National University Hospital, Seoul National University College of Medicine, Seoul, Republic of Korea. ${ }^{7}$ Department of Internal Medicine, Asan Medical Center, University of Ulsan College of Medicine, 86 Asanbeongwongil, Songpa-gu, Seoul 138-736, Republic of Korea. 


\section{References}

1. Anon: A clinical evaluation of the International Lymphoma Study Group classification of non-Hodgkin's lymphoma. The Non-Hodgkin's Lymphoma Classification Project. Blood 1997, 89:3909-3918.

2. Shipp MA, Harrington DP, Anderson JR, Armitage JO, B G: A predictive model for aggressive non-Hodgkin's lymphoma. The International NonHodgkin's Lymphoma Prognostic Factors Project. N Engl J Med 1993, 329:987-994.

3. Campbell J, Seymour JF, Matthews J, Wolf M, Stone J, Juneja S: The prognostic impact of bone marrow involvement in patients with diffuse large cell lymphoma varies according to the degree of infiltration and presence of discordant marrow involvement. Eur J Haematol 2006, 76:473-480

4. Chung R, Lai R, Wei P, Lee J, Hanson J, Belch AR, Turner AR, Reiman T: Concordant but not discordant bone marrow involvement in diffuse large B-cell lymphoma predicts a poor clinical outcome independent of the International Prognostic Index. Blood 2007, 110:1278-1282.

5. Gomyo H, Shimoyama M, Minagawa K, Yakushijin K, Urahama N, Okamura A, Yamamoto K, Ito M, Chihara K, Hayashi Y, Matsui T: Morphologic, flow cytometric and cytogenetic evaluation of bone marrow involvement in B-cell lymphoma. Haematol 2003, 88:1358-1365.

6. Talaulikar D, Shadbolt B, Dahlstrom JE, McDonald A: Routine use of ancillary investigations in staging diffuse large B-cell lymphoma improves the International Prognostic Index (IPI). J Hematol Oncol 2009, 2:49.

7. Merli M, Arcaini L, Boveri E, Rattotti S, Picone C, Passamonti F, Tenore A, Sozzani L, Lucioni M, Varettoni M, et al: Assessment of bone marrow involvement in non-Hodgkin's lymphomas: comparison between histology and flow cytometry. Eur J Haematol 2010, 85:405-415.

8. Lenz G, Staudt LM: Aggressive lymphomas. N Engl J Med 2010, 362:1417-1429.

9. Swerdlow SH, International Agency for Research on Cancer., World Health Organization: WHO classification of tumours of haematopoietic and lymphoid tissues. 4th edition. Lyon, France: International Agency for Research on Cancer; 2008.

10. Hans CP, Weisenburger DD, Greiner TC, Gascoyne RD, Delabie J, Ott G, MullerHermelink HK, Campo E, Braziel RM, Jaffe ES, et al: Confirmation of the molecular classification of diffuse large B-cell lymphoma by immunohistochemistry using a tissue microarray. Blood 2004, 103:275-282.

11. Thiele J, Zirbes TK, Kvasnicka HM, Fischer R: Focal lymphoid aggregates (nodules) in bone marrow biopsies: differentiation between benign hyperplasia and malignant lymphoma-a practical guideline. J Clin Pathol 1999, 52:294-300.

12. International Standing Committee on Human Cytogenetic Nomenclature, Shaffer LG, Slovak ML, Campbell L: ISCN 2009 : an international system for human cytogenetic nomenclature (2009). Basel ; Unionville, CT: Karger; 2009.

13. Slovak ML, Kopecky KJ, Cassileth PA, Harrington DH, Theil KS, Mohamed A, Paietta E, Willman CL, Head DR, Rowe JM, et al: Karyotypic analysis predicts outcome of preremission and postremission therapy in adult acute myeloid leukemia: a Southwest Oncology Group/Eastern Cooperative Oncology Group Study. Blood 2000, 96:4075-4083.

14. Gohring G, Michalova K, Beverloo HB, Betts D, Harbott J, Haas OA, Kerndrup G, Sainati L, Bergstraesser E, Hasle H, et al: Complex karyotype newly defined: the strongest prognostic factor in advanced childhood myelodysplastic syndrome. Blood 2010, 116:3766-3769.

15. Breems DA, Van Putten WL, De Greef GE, Van Zelderen-Bhola SL, GerssenSchoorl KB, Mellink CH, Nieuwint A, Jotterand M, Hagemeijer A, Beverloo $H B$, Lowenberg B: Monosomal karyotype in acute myeloid leukemia: a better indicator of poor prognosis than a complex karyotype. J Clin Oncol 2008, 26:4791-4797.

16. Vaidya R, Caramazza D, Begna KH, Gangat N, Van Dyke DL, Hanson CA, Pardanani A, Tefferi A: Monosomal karyotype in primary myelofibrosis is detrimental to both overall and leukemia-free survival. Blood 2011, 117:5612-5615.

17. Ciolino AL, Tang ME, Bryant R: Statistical treatment of fluorescence in situ hybridization validation data to generate normal reference ranges using Excel functions. J Mol Diagn 2009, 11:330-333.

18. Cheson BD, Pfistner B, Juweid ME, Gascoyne RD, Specht L, Horning SJ, Coiffier B, Fisher Rl, Hagenbeek A, Zucca E, et al: Revised response criteria for malignant lymphoma. J Clin Oncol 2007, 25:579-586.

19. Mitterbauer-Hohendanner G, Mannhalter C, Winkler K, Mitterbauer M, Skrabs C, Chott A, Simonitsch-Klupp I, Gleiss A, Lechner K, Jaeger U: Prognostic significance of molecular staging by PCR-amplification of immunoglobulin gene rearrangements in diffuse large B-cell lymphoma (DLBCL). Leuk 2004, 18:1102-1107.

20. Tierens AM, Holte H, Warsame A, Ikonomou IM, Wang J, Chan WC, Delabie J: Low levels of monoclonal small $B$ cells in the bone marrow of patients with diffuse large B-cell lymphoma of activated B-cell type but not of germinal center B-cell type. Haematol 2010, 95:1334-1341.

21. Gohring G, Giagounidis A, Busche G, Hofmann W, Kreipe HH, Fenaux P, Hellstrom-Lindberg E, Schlegelberger B: Cytogenetic follow-up by karyotyping and fluorescence in situ hybridization: implications for monitoring patients with myelodysplastic syndrome and deletion $5 \mathrm{q}$ treated with lenalidomide. Haematol 2011, 96:319-322.

22. United Kingdom Cancer Cytogenetics Group (UKCCG): Loss of the $Y$ chromosome from normal and neoplastic bone marrows. Genes Chromosomes Cancer 1992, 5:83-88.

23. Van Dyke DL, Wiktor A: Monosomy 21 in hematologic diseases. Cancer Genet Cytogenet 2003, 142:137-141

24. Gupta R, Soupir CP, Johari V, Hasserjian RP: Myelodysplastic syndrome with isolated deletion of chromosome 20q: an indolent disease with minimal morphological dysplasia and frequent thrombocytopenic presentation. Br J Haematol 2007, 139:265-268.

25. Giardino D, Corti C, Ballarati L, Colombo D, Sala E, Villa N, Piombo G, Pierluigi M, Faravelli F, Guerneri S, et al: De novo balanced chromosome rearrangements in prenatal diagnosis. Prenat Diagn 2009, 29:257-265.

26. Pasantes JJ, Wimmer R, Knebel S, Munch C, Kelbova C, Junge A, Kieback $P$, Kupferling $P$, Schempp W: 47, X, idic $(Y)$, inv $\operatorname{dup}(Y)$ : a non-mosaic case of a phenotypically normal boy with two different $Y$ isochromosomes and neocentromere formation. Cytogenet Genome Res 2012, 136:157-162.

27. Bea S, Zettl A, Wright G, Salaverria I, Jehn P, Moreno V, Burek C, Ott G, Puig $X$, Yang $L$, et al: Diffuse large B-cell lymphoma subgroups have distinct genetic profiles that influence tumor biology and improve geneexpression-based survival prediction. Blood 2005, 106:3183-3190.

28. Campbell L: Cytogenetics of lymphomas. Pathol 2005, 37:493-507.

29. Salido M, Baro C, Oscier D, Stamatopoulos K, Dierlamm J, Matutes E, Traverse-Glehen A, Berger F, Felman P, Thieblemont C, et al: Cytogenetic aberrations and their prognostic value in a series of 330 splenic marginal zone B-cell lymphomas: a multicenter study of the Splenic B-Cell Lymphoma Group. Blood 2010, 116:1479-1488.

30. Fleischman EW, Prigogina EL, llynskaya GW, Probatova NA, Konstantinova LN, Kruglova GV, Volkova MA, Osmanov DS: Chromosomal characteristics of malignant lymphoma. Hum Genet 1989, 82:343-348.

31. Hashimoto K, Miura I, Chyubachi A, Saito M, Miura AB: Correlations of chromosome abnormalities with histologic and immunologic characteristics in 49 patients from Akita, Japan with non-Hodgkin lymphoma. Cancer Genet Cytogenet 1995, 81:56-65.

32. Whang-Peng J, Knutsen T, Jaffe ES, Steinberg SM, Raffeld M, Zhao WP, Duffey $P$, Condron K, Yano T, Longo DL: Sequential analysis of 43 patients with nonHodgkin's lymphoma: clinical correlations with cytogenetic, histologic, immunophenotyping, and molecular studies. Blood 1995, 85:203-216.

33. Jerkeman M, Johansson B, Akerman M, Cavallin-Stahl E, Kristoffersson U, Mitelman F: Prognostic implications of cytogenetic aberrations in diffuse large B-cell lymphomas. Eur J Haematol 1999, 62:184-190.

34. Dave BJ, Nelson M, Pickering DL, Chan WC, Greiner TC, Weisenburger DD, Armitage JO, Sanger WG: Cytogenetic characterization of diffuse large cell lymphoma using multi-color fluorescence in situ hybridization. Cancer Genet Cytogenet 2002, 132:125-132.

35. Nanjangud G, Rao PH, Hegde A, Teruya-Feldstein J, Donnelly G, Qin J, Jhanwar SC, Zelenetz AD, Chaganti RS: Spectral karyotyping identifies new rearrangements, translocations, and clinical associations in diffuse large B-cell lymphoma. Blood 2002, 99:2554-2561.

36. Yoshioka T, Miura I, Kume M, Takahashi N, Okamoto M, Ichinohasama R, Yoshino T, Yamaguchi M, Hirokawa M, Sawada K, Nakamura S: Cytogenetic features of de novo CD5-positive diffuse large B-cell lymphoma: chromosome aberrations affecting $8 \mathrm{p} 21$ and $11 \mathrm{q} 13$ constitute major subgroups with different overall survival. Genes Chromosomes Cancer 2005, 42:149-157.

37. Monni O, Joensuu H, Franssila K, Knuutila S: DNA copy number changes in diffuse large B-cell lymphoma-comparative genomic hybridization study. Blood 1996, 87:5269-5278.

38. Berglund M, Enblad G, Flordal E, Lui WO, Backlin C, Thunberg U, Sundstrom C, Roos G, Allander SV, Erlanson M, et al: Chromosomal imbalances in 
diffuse large B-cell lymphoma detected by comparative genomic hybridization. Mod Pathol 2002, 15:807-816.

39. Bea S, Colomo L, Lopez-Guillermo A, Salaverria I, Puig X, Pinyol M, Rives S, Montserrat E, Campo E: Clinicopathologic significance and prognostic value of chromosomal imbalances in diffuse large B-cell lymphomas. J Clin Oncol 2004, 22:3498-3506.

40. Tagawa H, Suguro M, Tsuzuki S, Matsuo K, Karnan S, Ohshima K, Okamoto M, Morishima Y, Nakamura S, Seto M: Comparison of genome profiles for identification of distinct subgroups of diffuse large B-cell lymphoma. Blood 2005, 106:1770-1777.

41. Scandurra M, Mian M, Greiner TC, Rancoita PM, De Campos CP, Chan WC, Vose JM, Chigrinova E, Inghirami G, Chiappella A, et al: Genomic lesions associated with a different clinical outcome in diffuse large B-Cell lymphoma treated with R-CHOP-21. Br J Haematol 2010, 151:221-231.

42. Schlegelberger B, Zwingers T, Harder L, Nowotny H, Siebert R, Vesely M, Bartels H, Sonnen R, Hopfinger G, Nader A, et al: Clinicopathogenetic significance of chromosomal abnormalities in patients with blastic peripheral B-cell lymphoma. Kiel-Wien-Lymphoma Study Group. Blood 1999, 94:3114-3120.

43. Paulsson K, Jonson T, Ora I, Olofsson T, Panagopoulos I, Johansson B: Characterisation of genomic translocation breakpoints and identification of an alternative TCF3/PBX1 fusion transcript in $\mathrm{t}(1 ; 19)$ (q23;p13)-positive acute lymphoblastic leukaemias. Br J Haematol 2007, 138:196-201.

44. Calin GA, Croce CM: MicroRNAs and chromosomal abnormalities in cancer cells. Oncogene 2006, 25:6202-6210.

45. Scholtysik R, Nagel I, Kreuz M, Vater I, Giefing M, Schwaenen C, Wessendorf S, Trumper L, Loeffler M, Siebert R, Kuppers R: Recurrent deletions of the TNFSF7 and TNFSF9 genes in 19p13.3 in diffuse large B-cell and Burkitt lymphomas. Int J Cancer 2012, 131:E830-835.

46. Young KH, Leroy K, Moller MB, Colleoni GW, Sanchez-Beato M, Kerbauy FR, Haioun C, Eickhoff JC, Young AH, Gaulard P, et al: Structural profiles of TP53 gene mutations predict clinical outcome in diffuse large B-cell lymphoma: an international collaborative study. Blood 2008, 112:3088-3098.

47. Johnson NA, Savage KJ, Ludkovski O, Ben-Neriah S, Woods R, Steidl C, Dyer MJ, Siebert R, Kuruvilla J, Klasa R, et al: Lymphomas with concurrent BCL2 and MYC translocations: the critical factors associated with survival. Blood 2009, 114:2273-2279.

48. Savage KJ, Johnson NA, Ben-Neriah S, Connors JM, Sehn LH, Farinha P, Horsman DE, Gascoyne RD: MYC gene rearrangements are associated with a poor prognosis in diffuse large B-cell lymphoma patients treated with R-CHOP chemotherapy. Blood 2009, 114:3533-3537.

49. Tibiletti MG, Martin V, Bernasconi B, Del Curto B, Pecciarini L, Uccella S, Pruneri G, Ponzoni M, Mazzucchelli L, Martinelli G, et al: BCL2, BCL6, MYC, MALT 1, and BCL10 rearrangements in nodal diffuse large B-cell lymphomas: a multicenter evaluation of a new set of fluorescent in situ hybridization probes and correlation with clinical outcome. Hum Pathol 2009, 40:645-652.

50. Kremer M, Spitzer M, Mandl-Weber S, Stecker K, Schmidt B, Hofler H, Quintanilla-Martinez L, Fend F: Discordant bone marrow involvement in diffuse large B-cell lymphoma: comparative molecular analysis reveals a heterogeneous group of disorders. Lab Invest 2003, 83:107-114.

51. Chigrinova E, Mian M, Scandurra M, Greiner TC, Chan WC, Vose JM, Inghirami G, Chiappella A, Baldini L, Ponzoni M, et al: Diffuse large B-cell lymphoma with concordant bone marrow involvement has peculiar genomic profile and poor clinical outcome. Hematol Oncol 2011, 29:38-41.

doi:10.1186/1756-8722-6-76

Cite this article as: Kim et al: Clinical significance of cytogenetic aberrations in bone marrow of patients with diffuse large B-cell lymphoma: prognostic significance and relevance to histologic involvement. Journal of Hematology \& Oncology 2013 6:76.

\section{Submit your next manuscript to BioMed Central and take full advantage of:}

- Convenient online submission

- Thorough peer review

- No space constraints or color figure charges

- Immediate publication on acceptance

- Inclusion in PubMed, CAS, Scopus and Google Scholar

- Research which is freely available for redistribution

Submit your manuscript at www.biomedcentral.com/submit 